OPEN ACCESS

Edited by:

Mireille Alhouayek,

Catholic University of Louvain,

Belgium

Reviewed by:

Carles Barceló,

Balearic Islands Health Research

Institute (IdISBa), Spain

Maja T. Tomicic,

Johannes Gutenberg University

Mainz, Germany

${ }^{*}$ Correspondence:

Rakesh Naidu

kdrakeshna@hotmail.com

Specialty section:

This article was submitted to

Gastrointestinal and Hepatic

Pharmacology,

a section of the journal

Frontiers in Pharmacology

Received: 01 September 2021 Accepted: 05 November 2021 Published: 23 November 2021

Citation:

Hon KW, Zainal Abidin SA, Othman and Naidu $R$ (2021) The Crosstalk Between Signaling Pathways and

Cancer Metabolism in

Colorectal Cancer.

Front. Pharmacol. 12:768861. doi: 10.3389/fphar.2021.768861

\section{The Crosstalk Between Signaling Pathways and Cancer Metabolism in Colorectal Cancer}

\author{
Kha Wai Hon, Syafiq Asnawi Zainal Abidin, lekhsan Othman and Rakesh Naidu* \\ Jeffrey Cheah School of Medicine and Health Sciences, Monash University Malaysia, Bandar Sunway, Malaysia
}

Colorectal cancer $(\mathrm{CRC})$ is one of the most frequently diagnosed cancers worldwide. Metabolic reprogramming represents an important cancer hallmark in CRC. Reprogramming core metabolic pathways in cancer cells, such as glycolysis, glutaminolysis, oxidative phosphorylation, and lipid metabolism, is essential to increase energy production and biosynthesis of precursors required to support tumor initiation and progression. Accumulating evidence demonstrates that activation of oncogenes and loss of tumor suppressor genes regulate metabolic reprogramming through the downstream signaling pathways. Protein kinases, such as AKT and C-MYC, are the integral components that facilitate the crosstalk between signaling pathways and metabolic pathways in CRC. This review provides an insight into the crosstalk between signaling pathways and metabolic reprogramming in CRC. Targeting CRC metabolism could open a new avenue for developing CRC therapy by discovering metabolic inhibitors and repurposing protein kinase inhibitors/monoclonal antibodies.

Keywords: colorectal cancer, metabolism, metabolic reprogramming, protein kinase, signaling pathways

\section{INTRODUCTION}

Despite the advancement in early detection and medical treatments in recent decades, cancer incidence and mortality continue to increase gradually, as estimated in Global Cancer Statistic (GLOBOCAN) database under The International Agency for Research of Cancer (IARC) and the World Health Organization (WHO). Based on the latest GLOBOCAN 2021 statistics, colorectal cancer (CRC) remains the third most common cancer and the second leading cause of cancer mortality globally (Sung et al., 2021). CRC accounts for 10 percent of 19.3 million new cancer cases and 9.4 percent of about 10 million cancer deaths worldwide (Sung et al., 2021). The high incidence rate of CRC is correlated with genetics, environmental factors, and lifestyle development (Dunlop et al., 2013; Johnson et al., 2013; Rawla et al., 2019). Previous studies estimated that about $65-70$ percent of CRC is thoroughly sporadic with no known family history (Samadder et al., 2015). About 25 percent of CRC cases are known to have a family history related to inflammatory bowel syndrome (Yurgelun et al., 2017). Only 5 percent of CRC cases are hereditary CRC syndrome, namely FAP (familial adenomatous polyposis) and Lynch syndrome (Samadder et al., 2015). CRC arises from the glandular epithelial cells of the large intestine when specific cells undergo a series of genetic and epigenetic mutations to become hyper-proliferative and cancerous over time (Ewing et al., 2014; Dekker et al., 2019). These cancerous cells form a benign adenoma at an early stage, in which some progress into carcinoma and metastasize to other organs at the later stage of malignancy (Dekker et al., 2019).

Like any other cancer, CRC cells undergo rewiring of cellular metabolism via the dysregulation of oncogenes and tumor suppressors during carcinogenesis (Brown et al., 2018). Metabolic 
reprogramming is an essential cancer hallmark in many cancers, including CRC (Cantor and Sabatini, 2012). By altering core metabolism pathways, such as glutaminolysis, glycolysis, lipid synthesis, and mitochondrial oxidation, metabolic reprogramming allows CRC cells to sustain rapid cell proliferation with high demand for energy and biosynthetic precursors to drive tumor development and cancer metastasis (Brown et al., 2018). Regulation of metabolic reprogramming involves a complex network of different signaling pathways in cancer cells, which various protein kinases can regulate (GarciaOrtega et al., 2017; Lu and Hunter, 2018). Protein kinases (PTKs) are enzymes that selectively modify the biological activity of biomolecules (lipids, proteins, and carbohydrates) via phosphorylation with ATP as the primary source of phosphate (Cheng et al., 2011). Dysregulation of protein kinases has been reported in multiple cancers, such as breast (Templeton et al., 2014), stomach (Shiroki et al., 2017), pancreas (James et al., 2020), and CRC (Asante et al., 2019), to affect metabolic reprogramming of cancer cells through the manipulation of signaling pathways. This review will discuss the importance of protein kinases as crucial regulators of signaling pathways in the metabolic reprogramming of CRC cells. A deeper understanding of the protein kinases and signaling pathways involved in the metabolic reprogramming in CRC will provide insight into discovering new therapeutic targets.

\section{The Warburg Effect in Colorectal Cancer}

In 1924, Otto Warburg discovered that, even in the presence of oxygen, cancer cells preferentially alter the ATP production towards aerobic glycolysis followed by lactic acid fermentation rather than oxidative phosphorylation (OXPHOS) (Devic, 2016). Compared to normal cells, most pyruvate in cancer cells is distributed into lactate fermentation in the cytosol instead of entering the mitochondrial tricarboxylic acid (TCA) cycle and OXPHOS (Vaupel et al., 2019). The unique metabolic phenotype of cancer cells is known as the Warburg effect (Vaupel et al., 2019). In comparison, OXPHOS produces more ATP per molecule of glucose, but aerobic glycolysis produces ATP more rapidly, favoring the actively proliferating cancer cells (Vaupel et al., 2019). Aerobic glycolysis also generates more glycolytic intermediates and pyruvate to synthesize macromolecules and support ATP production (Blanco and Blanco, 2017b). Subsequently, pyruvate is converted into lactate to enter the Krebs cycle and rapidly produce ATP (Blanco and Blanco, 2017b). Other glycolytic intermediates such as glucose-6-phosphate, fructose-6-phosphate, and glyceraldehyde-3-phosphate are converted into macromolecules (nucleotides, phospholipids, and fatty acids) to sustain cell growth and maintenance (Blanco and Blanco, 2017c).

Certain protein kinases are involved in glucose uptake and aerobic glycolysis as rate-limiting enzymes, such as hexokinase (HK), phosphofructokinase (PFK), and pyruvate kinase (PK) (Blanco and Blanco, 2017b). Accumulated evidence shows that dysregulation of these glycolytic regulatory enzymes is vital to modulate the Warburg effect in CRC via different signaling pathways (Brown et al., 2018).
Hexokinase $(\mathrm{HK})$ serves as the rate-limiting enzyme to catalyze the first irreversible step of glucose uptake by converting glucose to glucose-6-phosphate (G6P) upon phosphorylation with ATP (Blanco and Blanco, 2017b). Interestingly, G6P then suppresses the activity of HKII through a feedback inhibition mechanism (Blanco and Blanco, 2017b). G6P is the precursor for major pathways of glucose metabolism, including glycolysis, pentose phosphate pathway, oxidative phosphorylation (OXPHOS), and hexosamine biosynthesis pathways (Blanco and Blanco, 2017b). Therefore, HK is regarded as an essential regulator of glucose metabolism. The mammalian $\mathrm{HK}$ family has five isoforms: HKI, HKII, HKIII, HKIV, and HKDC1 (HexoKinase Domain-Containing protein 1) (Wilson, 2003; Irwin and Tan, 2008). Among all, HKII is frequently upregulated in multiple cancers, including breast (SatoTadano et al., 2013), glioblastoma (Wolf et al., 2011), prostate (Lee et al., 2019), and CRC (Ho and Coomber, 2016). Previous studies report that HKII plays dual cancerpromoting effects by inducing glycolysis and inhibit apoptosis. HKII binds to voltage-dependent anion channel (VDAC) in the outer membrane of mitochondria to suppress apoptosis by closing the permeability transition pores and preventing cytochrome c release (Yuan et al., 2008; Tait and Green, 2013). Notably, growth factor-induced oncogenic signaling pathways, such as EGFR and PI3K/Akt/mTOR signaling, regulate the mitochondrial translocation of HKII (Makinoshima et al., 2014; Liu et al., 2015; Ciscato et al., 2020). Mitochondrial binding of HKII also reduces the feedback inhibition from G6P to increase its stability and promote glycolytic flux, producing more ATP (Wolf et al., 2011). HKII overexpression is correlated with poor prognosis in CRC and has been proposed as a therapeutic target due to its importance in glycolysis and cellular survival (Hamabe et al., 2014; Ho and Coomber, 2016; Krasnov et al., 2016).

\subsection{EGFR/Akt in the Warburg Effect}

Xanthohumol is a natural compound extracted from hops (Humulus lupulus), and it exerts antitumor effects in CRC cells (Jiang et al., 2018). Liu et al. discovered that xanthohumol inhibited glycolysis in CRC cells via EGFR/Akt/ HKII axis (Liu et al., 2019). Xanthohumol directly suppressed the phosphorylation of EGFR and EGFR downstream kinases Akt to downregulate the activity of HKII, resulting in a lower rate of glycolysis and activation of mitochondrial-induced apoptosis in CRC cells (Liu et al., 2019). Overexpression of HKII reversed the inhibitory effect of xanthohumol and increased the glycolytic rate in CRC cells (Liu et al., 2019). Epidermal growth factor receptor (EGFR), also known as ErbB1/Her1, is a member of the membrane-bound receptor tyrosine kinase family, which can be activated by binding of its specific ligands, namely epidermal growth factor (EGF) and transforming growth factor a (TGFa) (Wang, 2017). EGFR is overexpressed in many cancers to function as an oncogene (Nishimura et al., 2015; Cairns et al., 2018). Additionally, EGFR can be mutated in cancers to become constitutively active without ligand binding (Cairns et al., 2018). When activated, EGFR phosphorylates the 
downstream effectors and signaling pathways to initiate a wide range of oncogenic activities such as cell survival and proliferation (Templeton et al., 2014; Cairns et al., 2018; Fernandes et al., 2018).

Meanwhile, Akt is a serine/threonine kinase frequently upregulated in tumor cells, activated by a wide range of growth factors and receptor stimuli, such as EGFR, PI3K, and PTEN (Nitulescu et al., 2018). Akt mainly functions as a central anabolic and survival effector to regulate cellular metabolism and survival through the phosphorylation of target molecules at different cellular compartments (Song et al., 2019; Hoxhaj and Manning, 2020). The EGFR/Akt signaling cascade has been identified as a crucial oncogenic regulator in various cancers, including non-small cell lung cancer(NSCLC) (Chandrasekaran et al., 2017) and prostate cancer (Gan et al., 2010). Additionally, the direct interaction between HKII and the EGFR/Akt pathway could be essential to modulate cancer progression. Another study by Zou et al. reported that the ubiquitin-like protein FAT10 promoted bladder cancer progression by upregulating HKII via the EGFR/Akt pathway (Zou et al., 2021). FAT10 stabilizes EGFR expression by reducing its degradation and ubiquitination (Zou et al., 2021). Similarly, the EGFR/Akt/HKII regulatory circuit modulates the CRC metabolism. Thus, this axis could become a therapeutically significant target for CRC.

\subsection{C-MYC Signaling in the Warburg Effect}

The c-MYC is a member of the MYC family that includes MYCN and MYC (Rahl and Young, 2014). MYC encodes the Myc transcription factor, which dimerizes with Max to bind DNA and regulate about 15 percent of total gene expression in human cells (Dang et al., 2006). The c-MYC expression is tightly regulated by growth factor-dependent signals in normal cells (Dong et al., 2020). However, c-MYC is a proto-oncogene overexpressed in many cancers, including CRC (Gabay et al., 2014). The c-MYC dysregulation in cancers is mainly induced through gene amplification, chromosome translocation, superenhancer activation, and loss of upstream repressors to stabilize the c-MYC protein expression (Dong et al., 2020; Wolf and Eilers, 2020). c-MYC functions as a critical regulator of malignant transformation by promoting multiple processes, including cell proliferation, cell growth, and genomic instability (Gabay et al., 2014). More importantly, c-MYC contributes to metabolic reprogramming via several effective mechanisms, such as glycolysis, glutaminolysis, mitochondrial biogenesis, and lipid synthesis (Wahlstrom and Henriksson, 2015). Accumulated evidence suggests that c-MYC-driven metabolic reprogramming in cancer cells is mainly characterized by increased uptake of precursors, enhanced rate of glycolysis and glutaminolysis, as well as increased synthesis of fatty acids and nucleotides (Cunningham et al., 2014; Broecker-Preuss et al., 2017; Cai et al., 2019; Casciano et al., 2020). Tang et al. reported that lncRNA GLCC1 regulates CRC progression and glucose metabolism by stabilizing c-MYC to promote the transcription of glycolytic genes in CRC cells (Tang et al., 2019). GLCC1 was significantly upregulated in glucose-depleted CRC cells and bound explicitly with heat shock protein 90 (HSP90) chaperon upon glucose depletion (Tang et al., 2019). GLCC1 modulates the interaction between HSP90 and c-MYC complex to stabilize c-MYC from degradation (Tang et al., 2019). Indirectly, GLCC1 coordinates the localization and binding pattern of c-MYC genome-wide, promoting the expression of LDHA to upregulate glycolytic metabolism for CRC proliferation (Tang et al., 2019). Lactate dehydrogenase A (LDHA) is a cytosolic enzyme encoded by the LDHA gene on the short $\mathrm{p}$ arm of chromosome 11 (11p15.4), which plays a critical role in anaerobic and aerobic glycolysis (the Warburg effect) (Kolappan et al., 2015). LDHA facilitates the interconversion of pyruvate to lactate coupled with the recycling of $\mathrm{NAD}^{+}$from $\mathrm{NADH}$ during the last step of glycolysis (Blanco and Blanco, 2017b). LDHA is frequently upregulated in CRC and identified as a direct target gene of the c-MYC oncogenic transcription to reprogram cancer metabolism (Wang et al., 2015; Satoh et al., 2017).

Similarly, N-MYC downstream-regulated gene 2 (NDRG2), a well-known tumor suppressor, inhibits glycolysis in CRC cells by modulating c-MYC expression (Xu et al., 2015). NDRG2 is widely expressed in normal tissue and downregulated in various tumors, including CRC (Kloten et al., 2016; Zhang et al., 2017; Morishita et al., 2021). Overexpression of NDRG2 suppresses cellular growth, proliferation, and invasion in cancers (Li et al., 2013; Hong et al., 2016; Yang CL. et al., 2018; Kang et al., 2020). In CRC metabolism, NDRG2 inhibits c-MYC expression by suppressing $\beta$-catenin, the critical effector of the Wnt signaling pathway (Xu et al., 2015). Under normal conditions, $\beta$-catenin can be degraded via upstream regulators, such as adenomatous polyposis coli (APC), GSK-3 $\beta$, and casein kinase $1 \alpha$ (CK1 $\alpha$ ) (Duchartre et al., 2016). When Wnt signaling is often dysregulated in cancers, possibly due to APC mutation, cytoplasmic $\beta$-catenin translocates to the nucleus to activate $\mathrm{c}$-MYC transcription (Duchartre et al., 2016). NDRG2 directly inhibits $\beta$-catenin to repress the $\mathrm{c}-\mathrm{MYC}$ expression at the transcriptional level (Xu et al., 2015). c-MYC is the oncogenic transcriptional factor responsible for modulating the Warburg effect in CRC cells through the regulation of glucose transporters (GLUTs) and other glycolytic enzymes, namely HKII, PKM2, and LDHA (Wahlstrom and Henriksson, 2015). NDRG2 suppresses glycolysis in CRC cells by downregulating the expression of GLUT1, HKII, PKM2, and LDHA through c-MYC inhibition (Xu et al., 2015).

Another carcinogenic modulator, CD36, is a membrane glycoprotein that is associated with elevated fatty acids absorption to modulate cancer progression and metastasis in various cancers such as ovarian (Ladanyi et al., 2018), cervical (Yang P. et al., 2018), liver (Nath et al., 2015), and stomach (Pan et al., 2019). However, CD36 has been reported to target $\beta$-catenin/c-MYC-mediated glycolysis to repress CRC tumorigenesis (Fang et al., 2019). Early evidence showed that Wnt signaling could play a role in modulating the Warburg effect in CRC cells via the nuclear accumulation of $\beta$-catenin (Pate et al., 2014). CD36 was significantly downregulated in CRC tissue, and its expression level was negatively associated with cancer progression (Fang et al., 2019). Ectopic expression of CD36 directly promoted proteasome-dependent ubiquitination of Glypican 4 (GPC4), which is a member of the heparan sulfate 
proteoglycans (HSPGs) family (Zhao et al., 2016; Fang et al., 2019). Previous studies suggest that lipid raft localization of GPC4 is required to activate the $\mathrm{Wnt} / \beta$-catenin pathway (Fico et al., 2012; Sakane et al., 2012; Cao et al., 2018). GPC4 degradation reduced the nuclear translocation of $\beta$-catenin, leading to the downregulation of c-MYC and downstream glycolytic genes (GLUT1, LDHA, HK2, and PKM2) in CRC cells (Fang et al., 2019). Collectively, CD36 promotes the ubiquitination of GPC4 to de-activate $\beta$-catenin/c-MYC signaling cascades and downstream glycolytic target genes, repressing the glycolysis and tumorigenesis in CRC cells (Fang et al., 2019).

HK II is another downstream effector of c-MYC, which could be targeted to modulate glycolysis in CRC cells. Dioscin is a kind of steroid saponins isolated from Dioscoreae rhizome and Paridis rhizome, which has potent activities against various cancers, including CRC ( $\mathrm{Si}$ et al., 2016; Li et al., 2018; Mao et al., 2019). A recent study by $\mathrm{Wu}$ et al. showed that dioscin inhibits glycolysis and induces apoptosis in CRC cells by targeting c-MYC and HKII (Wu et al., 2020). Upon treatment with dioscin, the interaction between FBW7 and c-MYC in CRC cells was enhanced, leading to the ubiquitination of c-MYC (Wu et al., 2020). Consequently, dioscin promoted c-MYC degradation, and the downstream HKII was suppressed, resulting in glycolysis inhibition (Wu et al., 2020). Dioscin also impaired the interaction between HKII and VDAC-1 on the outer mitochondrial membrane, in which Bax could bind to the VDAC-1 more efficiently (Wu et al., 2020). This phenomenon increased membrane permeability and the release of cytochrome C, which ultimately led to cellular apoptosis (Wu et al., 2020). Thus, HKII is essential for dioscin-mediated glycolysis inhibition and apoptosis in CRC cells.

\subsection{STAT3 Signaling in the Warburg Effect}

Apart from EGFR/Akt and c-MYC signaling pathways, other pathways target HKII to modulate the glucose metabolism in CRC cells. The polo-like kinases (PLKs) belong to a family of highly conserved serine/threonine kinases, in which all five members (PLK1-5) possess a conserved N-terminal kinase domain and one or more polo-box domains (PBDs) at the C-terminus (Barr et al., 2004). Initially, PLKs were found to be critical regulators of cell cycle checkpoint, mitosis, and DNA damage response (Xie et al., 2005). Recent studies suggest that PLKs can modulate tumor growth, apoptosis, and metabolism (Ou et al., 2016; Gutteridge et al., 2017). Ou et al. revealed that PLK3 inhibits glucose metabolism in CRC by targeting HSP90/ STAT3/HKII signaling (Ou et al., 2019). PLK3 was significantly downregulated in CRC tissues and correlated with poor prognosis (Ou et al., 2016; Ou et al., 2019). PLK3 was directly bound to HSP90 to trigger proteasome-mediated degradation of HSP90, which reduced the phosphorylation of signal transducer and activator of transcription 3 (STAT3) at S727 residue (Ou et al., 2019). STAT3 directly binds to the promoter region of the HKII gene and upregulates the protein expression HKII. The STAT3 dephosphorylation downregulated the transcriptional activation of HKII, resulting in a lower glycolytic rate in CRC cells (Ou et al., 2019). The STAT family consists of seven proteins (STAT 1, 2, 3, 4, 5a, 5b, and 6), which have dual roles as signaling molecules and transcription factors (Villarino et al., 2015). STATs transduce signals from activated cytokine and growth factor receptors into the nucleus to initiate the transcription of target genes (Villarino et al., 2015). Specific cytokines and growth factors activate each STAT protein to regulate downstream target genes. For instance, cytokine receptors activate receptorassociated tyrosine kinases, such as the Janus kinase (JAK) family kinases, to phosphorylate the tyrosine 705 residue (Y705) in STAT3 protein (Parganas et al., 1998). Growth factor receptors associated with their intrinsic receptor tyrosine kinase (RTK) phosphorylate STAT3 at the same tyrosine 705 residue (Y705).

STAT3 is activated in response to a defined set of cytokines, namely IL-6, interferon-gamma (IFN $\gamma$ ), and erythropoietin, in addition to growth factors including epidermal growth factor (EGF) and fibroblast growth factor (FGF) (O'Sullivan et al., 2016). Tyrosine phosphorylation activates STAT3 to undergo homo/hetero-dimerization with another STAT protein(O'Sullivan et al., 2016). STAT3 dimers bind to specific DNA response elements in the promoter regions of target genes to regulate the gene transcription (O'Sullivan et al., 2016). Activated STAT3 dimer induces the expression of multiple genes associated with anti-apoptosis, proliferation, angiogenic, and metastatic properties in cancer cells (Timofeeva et al., 2013; Liu et al., 2015; Zhu et al., 2019). Moreover, serine/threonine kinases phosphorylate STAT3 on S727 in the cytoplasm or nucleus (Zhang et al., 1995). The serine phosphorylation of STAT3 is required for maximal transcriptional activity but not DNA binding (Wen et al., 1995). Multiple kinases are responsible for S727 phosphorylation, more prominently the mitogenactivated protein kinase (MAPK) family members (Shaheen and Broxmeyer, 2018). The MAPK family consists of the extracellular signal-regulated kinase (ERK) as well as JNK/ stress-activated protein kinase and p38/HOG1 (p38 MAPK) (Shaheen and Broxmeyer, 2018). STAT3 signaling is well studied as a significant intrinsic pathway for cancer inflammation due to its frequent activation in cancer cells that promotes inflammatory genes and suppresses anti-tumor immunity (Yu et al., 2009). Nevertheless, recent studies suggest that STAT3 signaling contributes to metabolic reprogramming in cancers. Lin et al. reported that palmitic acid inhibits glycolysis in hepatocellular carcinoma by silencing the STAT3 pathway (Lin et al., 2017). STAT3 signaling is also essential in PKM2-mediated glucose metabolism in breast cancer cells via the let-7a-5p/Stat3/ hnRNP-A1 regulatory feedback loop (Yao A. et al., 2019).

It was observed that STAT3 signaling plays a crucial role in the PLK3-inhibited glucose metabolism of CRC cells by targeting HKII expression (Ou et al., 2019). The interplay between STAT3 signaling and c-MYC has altered glycolysis in CRC cells in response to inflammation ( $\mathrm{Qu}$ et al., 2017). IL-6 is a proinflammatory cytokine frequently detected in the tumor microenvironment to induce inflammation and activate STAT3 signaling in cancer cells (Yu et al., 2009; Kim et al., 2016; Arora et al., 2018). In vitro studies revealed that the addition of IL-6 into CRC cell lines activated the phosphorylation of STAT3 and increased the expression of c-MYC and glycolytic enzymes, such as GLUT1 and LDH, resulting in higher glucose 
uptake and lactate production (Qu et al., 2017). These results suggest that inflammation could induce the reprogramming of glucose metabolism in CRC cells via the STAT3/c-MYC pathway. JAK2 is an upstream regulator of STAT3, which phosphorylates STAT3 at the Y705 residue. A recent study by Li et al. identified that JAK2/STAT3 signaling was targeted by atractylenolide-I to induce apoptosis and suppress glycolysis in CRC cells (Li Y. et al., 2020). Atractylenolide-I (AT-I) is a natural derivative of Rhizoma Atractylodis macrocephalus that has been shown to demonstrate anti-tumor activities in a wide range of cancers. Mechanistically, AT-I could directly bind to JAK2 to inhibit the JAK2 activity and suppress the downstream phosphorylation of STAT3 (Li Y. et al., 2020). Subsequently, the inactivation of STAT3 contributed to the downregulation of HKII, resulting in a lower rate of glycolysis and lactate production in CRC cells (Li Y. et al., 2020). Hence, AT-I inhibits glycolysis via JAK2/STAT3 signaling to suppress HKII expression in CRC cells (Li Y. et al., 2020).

\subsection{The PKM2 Paradox in the Warburg Effect}

Pyruvate kinase $(\mathrm{PK})$ is a rate-limiting enzyme in the final, irreversible step of the glycolysis, which is responsible for catalyzing the transphosphorylation between phosphoenolpyruvate and ADP to generate pyruvate and ATP (Blanco and Blanco, 2017b). There are four mammalian PK isoforms: PKL, PKR, PKM1, and PKM2, each with distinct kinetic properties and tissue distribution (Clower et al., 2010). PKL is mainly expressed in the liver and kidneys, while PKR is exclusively expressed in red blood cells (Israelsen et al., 2013). PKM1 is primarily expressed in differentiated tissues with high energetic demands, such as myocardium, skeletal muscle, and brain tissue (Chiavarina et al., 2011). PKM2 is distributed in tissues, such as the brain and liver, and is highly expressed in rapidly proliferating tissues, including cancers (Shiroki et al., 2017). The PK isoforms are encoded by two genes (PKLR and $\mathrm{PKM})$, respectively, through the alternative splicing of pyruvate kinase mRNA (PKL and PKR; PKM1 and PKM2) (Chen et al., 2010). The human PKM gene with a length of 12 exons is alternatively spliced to generate transcripts based on the mutually exclusive selection between 9th and 10th exons: exon 9 is specific to PKM1, exon 10 is specific to PKM2 (Israelsen and Vander Heiden, 2015). Multiple splicing factors regulate the $\mathrm{PKM} 1 / \mathrm{PKM} 2$ ratio in cancerous tissue, in which PKM2 is more favorable in most cancer types to modulate the Warburg effect (Israelsen et al., 2013). For instance, polypyrimidine tract binding protein (PTB), heterogeneous nuclear ribonucleoprotein A1 (HNRNPA1), and A2 (HNRNPA2B1) repress exon 9 and promote exon 10 to upregulate the PKM2 expression (Clower et al., 2010). Another splicing factor, namely the serine/argininerich splicing factor 3 (SRSF3), directly binds the PKM transcript to promote the inclusion of exon 10 for enhancing the PKM2 expression (Chen et al., 2010). Previous evidence also suggests that c-MYC activates the expression of HNRNPs to maintain a high PKM2/PKM1 ratio in cancer cells (David et al., 2010).

PKM2 exists in two oligomeric states: an active tetramer and a less active dimer/monomer, due to tetramerization upon binding with fructose-1,6-bisphosphate (FBP) (Sciacovelli et al., 2014). The moderately active, dimer form of PKM2 mainly participates in the Warburg effect in cancers by producing glycolytic intermediates to support tumor growth and proliferation. The PKM2 dimers also induce transcriptional co-activation and function as protein kinase targeting histones and transcription factors (Lu, 2012). PKM2 dimers translocate into the cell nucleus upon signaling from the extracellular signal-regulated kinase (ERK1/2) to initiate the expression of other glycolytic genes (GLUT1, LDHA, PDK) (Yang et al., 2012). The nuclear translocation of PKM2 is crucial for the autoregulation of PKM2 expression by upregulating its upstream activators, such as HIF1a and $\beta$-catenin (Luo et al., 2011; Yang et al., 2012; Prigione et al., 2014). More importantly, nuclear PKM2 interacts with HIFl $\alpha$ and $\beta$-catenin to regulate the expression of glycolytic enzymes and initiate the Warburg effect in cancer cells (Luo et al., 2011; Yang et al., 2011). In contrast, the tetramer form of PKM2 is fully active to maximize the efficiency of glycolysis and generate pyruvate for the utilization of oxidative phosphorylation but is excluded from nuclear translocation (Prakasam and Bamezai, 2018).

Recently, Sam68, an RNA-binding protein (RBP), has been identified to regulate glycolysis in CRC cells by controlling the alternative splicing of the PKM gene (Zhao J. et al., 2020). Sam68 is well recognized as a critical oncogenic factor associated with cancer progression and poor prognosis in CRC (Liao et al., 2013; Fu et al., 2016; Wang et al., 2018). Ectopic expression of Sam68 upregulates the glycolysis and proliferation in CRC cells, associated with decreased PKM1/ PKM2 ratio (Zhao J. et al., 2020). Sam68 binds to the EI9 region of the PKM gene to promote the inclusion of exon 9 and enhance the formation of PKM2 mRNA (Zhao J. et al., 2020). Overexpression of Sam68 significantly reduces the $\mathrm{PKM} 1 / \mathrm{PKM} 2$ ratio in CRC cells, resulting in the metabolic shift from oxidative phosphorylation to glycolysis (Zhao J. et al., 2020). Sam68 increases the PKM2 mRNA transport into the cytoplasm to enhance the PKM2 protein synthesis, promoting the pyruvate kinase activity and lactate production in CRC cells (Zhao J. et al., 2020). In addition, polypyrimidine tract binding protein 1 (PTB1) is a positive regulator of the Warburg effect in cancer cells by regulating the PKM2 expression (Clower et al., 2010). PTB1 is an exonic splicing silencer of the PKM mRNA that promotes the PKM2 expression by including exon 10 in alternative splicing $(\mathrm{He}$ et al., 2014). c-MYC can regulate PTB1 to promote cancer progression and the Warburg effect (David et al., 2010). Taniguchi et al. have presented several works on the regulatory role of miR-124 on PTB1 and PKM1/PKM2 ratio in modulating the Warburg effect in CRC (Taniguchi et al., 2015a; Taniguchi et al., 2015b). MiR-124 was downregulated in CRC clinical samples, while in vitro analysis revealed that miR-124 induced apoptosis and suppressed the Warburg effect in CRC cells (Taniguchi et al., 2015b). PTB1 promotes the production of PKM2, which inhibits miR-124 in a feedback loop (Taniguchi et al., 2015b). MiR-124 induces the switching of PKM isoforms from PKM2 to PKM1 by downregulating PTB1 
and its upstream regulators, namely c-MYC, E2F1, and STAT3 (Taniguchi et al., 2015b).

In addition, miR-124 can also regulate the Warburg effect in CRC cells via the DDX6/c-MYC/PTB1 positive-feedback mechanism (Taniguchi et al., 2015a). DDX6 is an oncogenic RNA helicase frequently overexpressed in multiple cancers, including CRC (Akao et al., 2006; Cordin et al., 2006; Akao, 2009; Tajirika et al., 2018). DDX6 expression is associated with the IRES-dependent c-MYC translation to regulate cancer cell growth and differentiation (Hashimoto et al., 2001; Akao et al., 2006; Taniguchi et al., 2018). DDX6 is significantly overexpressed in CRC tissues, in which the authors suggest that low expression of miR-124 contributes to the high DDX6 expression (Taniguchi et al., 2015a). MiR-124 directly targets DDX6 in CRC cells, in which miR-124 knockdown releases DDX6 to promote the c-MYC expression, and c-MYC upregulates PTB1 directly, contributing to the Warburg effect (Taniguchi et al., 2015a). PTB1 knockdown upregulates the miR-124 expression, subsequently suppressing the expression of DDX6 and c-MYC and inhibiting the Warburg effect in CRC cells (Taniguchi et al., 2015a). All this evidence supports that PTB1 is an essential modulator of CRC metabolism that can be regulated by miRNAs and oncogenic upstream activators, like c-MYC, to modulate the expression of PKM1 and PKM2 in the Warburg effect. Evidence shows that modulation of the Warburg effect involving the metabolic role of PKM2 could lead to the acquisition of other cancer phenotypes, such as chemoresistance. CD44 is a non-kinase transmembrane glycoprotein frequently overexpressed in cancers and cancer stem cells (Chen et al., 2018). CD44 functions as an adhesion molecule in many aspects of tumorigenesis, including migration, proliferation, and metastasis, as well as to function as a surface marker for cancer stem cells (Du et al., 2008; Liu et al., 2011; Louderbough and Schroeder, 2011; Cho et al., 2012; Wang et al., 2012; Senbanjo and Chellaiah, 2017). Overexpression of CD44 directly phosphorylates PKM2 at threonine (T105) residue to suppress its glycolytic activity and promote the Warburg effect in CRC cells (Tamada et al., 2012). CD44 knockdown also induces the metabolic shift from aerobic glycolysis to mitochondrial respiration with increased reactive oxygen species (ROS) production, which significantly re-sensitizes CRC cells towards cisplatin (Tamada et al., 2012). Hence, PKM2 is crucial for the CD44-mediated Warburg effect with enhanced cisplatin resistance in CRC cells.

Multiple signaling pathways regulate the metabolic role of PKM2 in CRC cells. The Wnt/ $\beta$-catenin signaling pathway is aberrantly activated in CRC due to the adenomatous polyposis coli (APC) gene mutation (loss of function) in nearly 90 percent of CRC patients (Coppede et al., 2014). APC protein is required to form the $\beta$-catenin destruction complex for $\beta$-catenin degradation and inhibition of the $\mathrm{Wnt} / \beta$-catenin signaling pathway (MacDonald et al., 2009). The loss of function in the APC gene is commonly associated with the early transformation of normal colon epithelium into adenoma (Powell et al., 1992). Mutant APC protein cannot form the destruction complex, leading to stabilization and accumulation of $\beta$-catenin expression in the cytosol (Requena and Garcia-Buitrago,

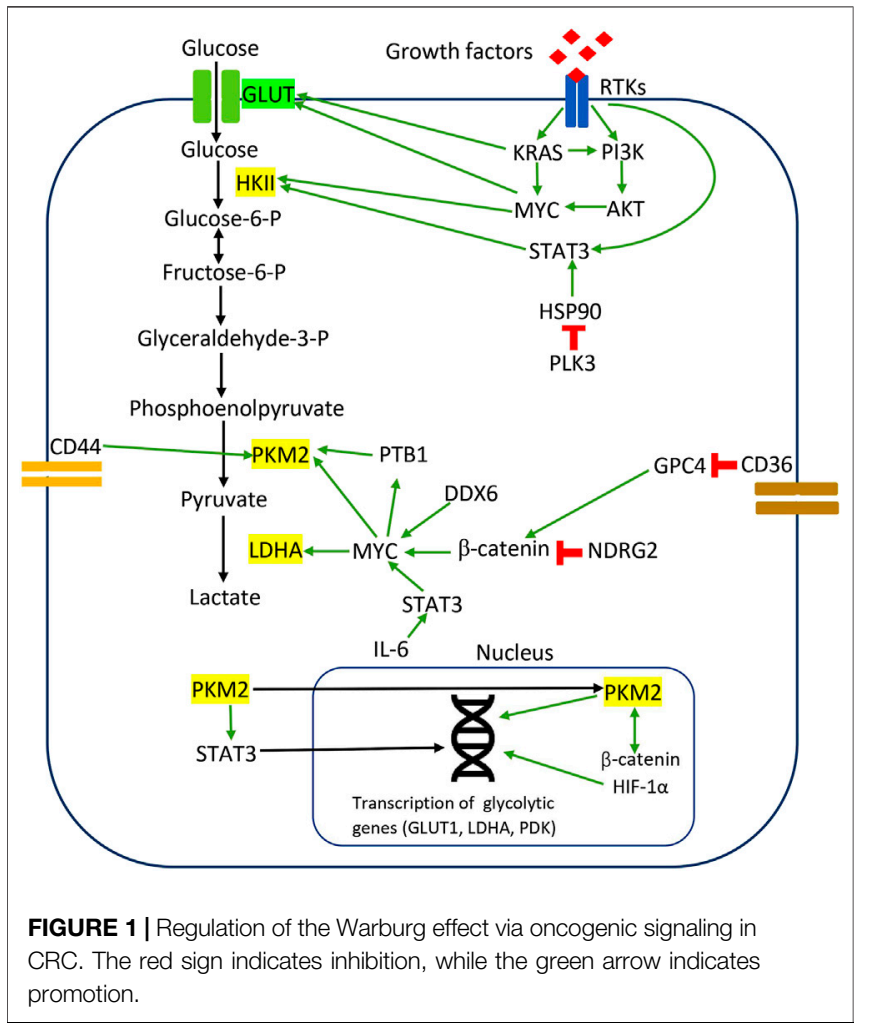

2020). The subsequent nuclear translocation of $\beta$-catenin activates inappropriate target genes, namely c-MYC and cyclin $\mathrm{D}$, associated with tumor proliferation, migration, invasion, and metastasis (Nguyen and Duong, 2018). More recently, the APC mutation in CRC cells has been reported to induce the Warburg effect via the $\mathrm{Wnt} / \beta$-catenin signaling pathway to target PKM2 (Cha et al., 2021). The loss of function in APC stabilizes the $\beta$-catenin and increases the nuclear translocation of $\beta$-catenin (Cha et al., 2021). Subsequently, this enhances the $\beta$-catenin/Tcf4 binding on PKM2 promoter regions and promotes PKM2 transcription (Cha et al., 2021). The PKM2 upregulation further increases the expression of other glycolytic enzymes, namely LDHA, GLUT1, PFK1-M, and PFKBP1, to enhance the Warburg effect in CRC cells (Cha et al., 2021). PKM2 also accelerates the activation of $\mathrm{Wnt} / \beta$-catenin signaling via a positive feedback loop in CRC cells (Cha et al., 2021). Collectively, the $\mathrm{Wnt} / \beta$-catenin signaling activated by APC mutation requires PKM2 as the critical mediator to modulate the Warburg effect in CRC.

In CRC, PKM2 induces direct phosphorylation of transcription activators and signaling molecules to mediate metabolic reprogramming and proliferation. Previous studies observed that PKM2 phosphorylated STAT3 at Tyr705 to activate STAT3-controlled genes, namely MEK5, for cell proliferation (Gao et al., 2012). Yang et al. reported that PKM2 facilitates CRC cell migration via the STAT3 signaling cascade (Yang $P$. et al., 2014). PKM2 overexpression in DLD1 cells upregulated STAT3 gene transcription and activated downstream snail-2 and $\beta 1$ - 
integrin-FAK signaling to induce tumor migration (Yang P. et al., 2014). PKM2 overexpression facilitated STAT3 nuclear translocation to upregulate the expression and function of PKM2 in migration and adhesion-associated signaling, suggesting the feedback mechanism between PKM2 and STAT3 (Yang P. et al., 2014). These results demonstrate that the protein kinase activities of dimeric PKM2 but not its metabolic functions are essential for CRC cell migration and cell adhesion. Figure 1 illustrates the regulation of the Warburg effect via oncogenic signaling in CRC.

\section{PKM2 in Glutaminolysis}

Glutamine is the most abundant non-essential amino acid in most cancer cells, which is highly required for cellular proliferation (Sciacovelli et al., 2014). Glutamine is catalyzed by glutaminase (GLS) to generate glutamate and converted into other intermediates, namely a-ketoglutarate, pyruvate, lactate, and malate, which can be utilized in different metabolic pathways (Blanco and Blanco, 2017a). Hence, glutamine metabolism or glutaminolysis is equally essential in the metabolic reprogramming of CRC cells by supporting ATP production and biosynthesis of proteins, lipids, and nucleic acids. The less glycolytic, dimer form of PKM2 is crucial to coordinate the metabolism change between glycolysis and glutaminolysis in CRC cells ( $\mathrm{Li}$ L. et al., 2020). PKM2 dimer facilitates glutaminolysis upon EGFR stimulation by promoting IRESdependent c-MYC translation (Li L. et al., 2020). Previously, c-MYC regulates PKM2 expression by controlling PKM2 premRNA splicing, and subsequently, PKM2 regulates c-MYC gene transcription in a direct feedback mechanism (David et al., 2010; Luo et al., 2011; Yang et al., 2012). The recent work by Li et al. demonstrates that PKM2 interacts with the c-MYC/IRES complex to regulate c-MYC translation via another IRESdependent mechanism (Li L. et al., 2020). There are two pathways in c-MYC protein synthesis at the translational level: canonical cap-dependent translation and internal ribosome entry site (IRES)-dependent translation (Godet et al., 2019). The IRESdependent c-MYC translation is an oncogenic pathway that allows the c-MYC protein synthesis under critical conditions, such as apoptosis and hypoxia, when the canonical capdependent translation is largely attenuated (Stoneley et al., 2000; Spriggs et al., 2009). As PKM2 dimer promotes IRESdependent c-MYC translation in CRC cells, the activated c-MYC protein subsequently upregulates GLS-I to increase glutamine consumption (Li L. et al., 2020). Glutaminase I (GLS-I) is the mitochondrial enzyme that catalyzes the first, irreversible step of glutaminolysis by converting glutamine to glutamate (Jin et al., 2016). GLS-I plays a vital role in glutaminolysis and is frequently dysregulated in cancers (Pan et al., 2015; Daemen et al., 2018; Xiang et al., 2019; Ren et al., 2020). The less active form of PKM2 dimer modulates glutaminolysis in CRC cells by targeting IRESdependent c-MYC translation to coordinate cell response to hypoxia environment. The oligomeric switching between tetramer and dimer forms of PKM2 corresponds to the metabolic change between glycolysis and glutaminolysis in CRC cells upon the stimulation of growth factors and environmental stress.
Another study proposed that PKM2 depletion could promote the $\beta$-catenin signaling and its downstream c-MYC to enhance glutamine metabolism in CRC cells (Wu et al., 2014). CRC cells enhance glutamine metabolism to compensate for glycolysis impairment upon PKM depletion (Wu et al., 2014). Previously, it was shown that c-MYC regulates mitochondrial glutaminase expression and glutamine metabolism in cancer cells (Gao et al., 2009). Interestingly, PKM2-knockdown in CRC cells significantly upregulates $\mathrm{c}-\mathrm{MYC}$ protein expression and $\beta$-catenin expression at mRNA and protein levels, suggesting that PKM2 regulates glutaminolysis mainly via $\beta$-catenin/c-MYC signaling (Wu et al., 2014). Nuclear translocation of dimeric PKM2 negatively regulates the $\beta$-catenin mRNA at the transcriptional level through the action of miR-200a that directly targets the 3' UTR of $\beta$-catenin mRNA (Wu et al., 2014). Collectively, PKM2 functions as the protein kinase that negatively affects the $\beta$-catenin/c-MYC signaling pathway through miR-200a to modulate glutaminolysis in CRC cells.

\section{KRAS Mutations and PI3K Signaling in Glutamine Metabolism}

KRAS mutation is common in many cancers, including CRC (Ewing et al., 2014). KRAS mutation causes the protein to become constitutively active AND promote the signaling through growth and survival pathways, namely the phosphatidylinositol 3-kinase (PI3K) and mitogen-activated protein kinase (MAPK) cascades (Kerk et al., 2021). Mutant KRAS has been used as a clinical biomarker to predict resistance to anti-epidermal growth factor receptor (EGFR) therapy in treating metastatic CRC (Kudryavtseva et al., 2016). Previous studies suggest that KRAS mutation could be essential to modulate glucose uptake, glutaminolysis, and mitochondrial ROS production in CRC metabolism. Yun et al. reported that CRC cell lines with mutations in either KRAS or BRAF upregulate GLUT-1 with increased glucose uptake and lactate production (Yun et al., 2009). Another proteomic study showed that mutant KRAS and BRAF in CRC cell lines could impact multiple aspects of metabolism, including glycolysis, phosphoserine biosynthesis, glutamine metabolism, and the non-oxidative pentose phosphate pathway, by modulating the expression of corresponding proteins/enzymes (Hutton et al., 2016). KRAS and BRAF mutations contribute to metabolic reprogramming in CRC to support rapid proliferation and sustain biosynthetic needs. Additionally, it was demonstrated that glutamine-based mitochondrial metabolism is essential for KRAS mutant CRC cells to support cell growth and proliferation (Weinberg et al., 2010). KRAS mutant CRC cells acquire a high glycolytic flux to provide glycolytic intermediates for the pentose phosphate pathway to produce nucleotides and phospholipids for rapid proliferation (Weinberg et al., 2010). Glutamine metabolism provides the alternative carbon source for the TCA cycle in mitochondrial respiration to generate ATP for cellular proliferation and tumorigenesis (Weinberg et al., 2010).

Knockdown of the glutamine transporter in KRAS mutant CRC cells reduces the proliferation rate and inhibits other oncogenic activities, including migration, invasion, and 
metastasis (Wong et al., 2016). A recent study by Wong et al. also reveals that glutamine metabolism in mutant KRAS CRC cells contributes to the activation of Wnt signaling, cancer stemness, and drug resistance by reducing DNA methylation through SLC25A22, a mitochondrial glutamine transporter (Wong et al., 2020). SLC25A22 expression is associated with poor prognosis in advanced-stage CRC with mutant KRAS (Wong et al., 2020). SLC25A22 is upregulated in mutant KRAS CRC cells to induce succinate accumulation in the cell nucleus and subsequently modulate epigenetic regulators' expression to enhance WNT/ $\beta$-catenin signaling and LGR5 expression (Wong et al., 2020). Indirectly, SLC25A22 promotes cancer stemness and drug resistance in CRC cells.

Phosphoinositide 3-kinases (PI3Ks) comprise a large family of lipid kinases that function as intracellular signal transducers (Noorolyai et al., 2019). PI3K signaling can be activated through the upstream RAS isoforms, tyrosine kinase receptors, and mutations in PI3K signaling components (43). The activation of the PI3K pathway is mainly associated with cell cycle progression, proliferation, differentiation, and metabolism in cancer cells (Fernandes et al., 2018). PIK3CA gene encodes the p110a catalytic subunit of PI3K, and its mutation represents one of the most common genetic aberrations in human cancers (Zardavas et al., 2014). PI3KCA mutations reprogram glutamine metabolism in CRC cells by upregulating glutamate pyruvate transaminase 2 (GPT2) (Hao et al., 2016). Consequently, CRC cells with PI3KCA mutations are more sensitive to glutamine deprivation and substantially increase glutamine metabolism to replenish the TCA cycle and generate ATP (Hao et al., 2016). Mutant p110a upregulates GPT2 gene expression through novel PDK1-RSK2-ATF4 signaling that is AKT-independent (Hao et al., 2016). Mutant p110 a activates RSK2 kinase through pyruvate dehydrogenase kinase 1 (PDK1) (Hao et al., 2016). PDK1 is a downstream effector of $\mathrm{PI} 3 \mathrm{~K}$ via the signal transduction from phosphatidylinositol-3,4,5-triphosphate (PIP3), whereas RSK2 is a serine/threonine kinase that phosphorylates ATF4 at the serine 245 residue (S245) (Frodin et al., 2002; Hao et al., 2014). Activated RSK2 phosphorylates ATF4 to recruit the deubiquitinase USP8, preventing ATF4 from ubiquitinmediated degradation (Hao et al., 2016). ATF4 (activating transcription factor 4) has been reported to modulate glutamine metabolism in different cancer studies (Qing et al., 2012; Csibi et al., 2013). Eventually, ATF4 activates GPT2 gene transcription directly to promote PI3K-mediated glutamine metabolism (Hao et al., 2016).

\section{SIGNALING PATHWAYS IN OXIDATIVE PHOSPHORYLATION}

KRAS mutation is also associated with the regulation of mitochondrial respiration in CRC cells. Mitochondrial respiration comprises two major components: the tricarboxylic acid cycle (TCA cycle) and oxidative phosphorylation (OXPHOS) (Blanco and Blanco, 2017c). TCA cycle occurs in the inner mitochondrial space to generate $\mathrm{NADH}$ and FADH2 via acetyl-CoA metabolism (Blanco and Blanco, 2017b). The $\mathrm{NADH}$ and $\mathrm{FADH}_{2}$ generated by the TCA cycle will be oxidized in OXPHOS, which takes place on the inner membrane of mitochondria, to generate ATP and reactive oxygen species (ROS) as a byproduct (Blanco and Blanco, 2017b). In CRC, KRAS mutations have decreased ROS production and enhanced mitochondrial OXPHOS efficiency by activating mitochondrial phospholipid synthesis via the upregulation of transcriptional factors HIF-1 $\alpha$ and HIF-2 $\alpha$ (Chun et al., 2010). The hypoxia-inducible factors-1 $\alpha$ and $-2 a$ (HIF-1 $\alpha$ and HIF-2 $\alpha$ ) are frequently upregulated in cancers and associated with tumor angiogenesis, cell growth and survival, and metastasis (Li T. et al., 2020). It was shown that HIF-1a and HIF$2 \alpha$ proteins translocate to the nucleus and dimerize with HIF-1 $\beta$ to transactivate target genes (Koh et al., 2011). Previously, HIF-1a and HIF-2 $\alpha$ regulated the exchange of COX4 (cytochrome $c$ oxidase 4) subunits under hypoxic conditions to increase mitochondrial respiration efficiency and reduce ROS production (Fukuda et al., 2007).

\section{SIGNALING PATHWAYS IN LIPID METABOLISM}

Dysregulation of lipid metabolism is equally essential for CRC tumor growth and survival. Fatty acids are essential components of all biological membranes and the critical carbon source for energy metabolism in the TCA cycle and OXPHOS (Blanco and Blanco, 2017d). Fatty acids can act as signaling molecules associated with multiple aspects of tumorigenesis, such as migration, invasion, and drug resistance (Nath et al., 2015; Blanco and Blanco, 2017c; Ladanyi et al., 2018; Pan et al., 2019). In CRC, multiple studies have shown that the de novo synthesis of fatty acids is enhanced with the upregulation of critical enzymes, including ATP citrate lyase (ACLY), acetyl CoA carboxylase (ACC), and fatty acid synthase (FASN) (Zaytseva et al., 2012; Hofmanova et al., 2021). Upregulation of FASN has been reported in mutant KRAS cell lines, which supports cellular respiration through mitochondrial fatty acid $\beta$-oxidation (FAO) (Zaytseva et al., 2015). FAO is the primary pathway for degrading long-chain fatty acids to produce acetyl-CoA, which participates in the TCA cycle to replenish ATP, NADPH, NADH, and $\mathrm{FADH}_{2}$ (Houten et al., 2016). A recent study by Wang et al. demonstrates that epigallocatechin-3-gallate (EGCG), a water-soluble polyphenol and the main active ingredient of green tea, inhibits fatty acid de novo synthesis and lipid droplets formation in CRC cells via AMPK activation (Wang et al., 2021). AMP-activated protein kinase (AMPK) is a serine/ threonine protein kinase, which serves as a metabolic sensor and core regulator of energy metabolism in cancers (Steinberg and Carling, 2019). Previously, AMPK activation could decrease de novo lipogenesis (Smith and Steinberg, 2017). In addition, studies have shown that AMPK activation inhibits the Warburg effect and de novo lipogenesis while increasing OXPHOS to suppress cancer cell growth (Chen et al., 2012; Smith and Steinberg, 2017; Holczer et al., 2018). EGCG significantly increases the phosphorylation of AMPKa (Thr172) to inhibit 


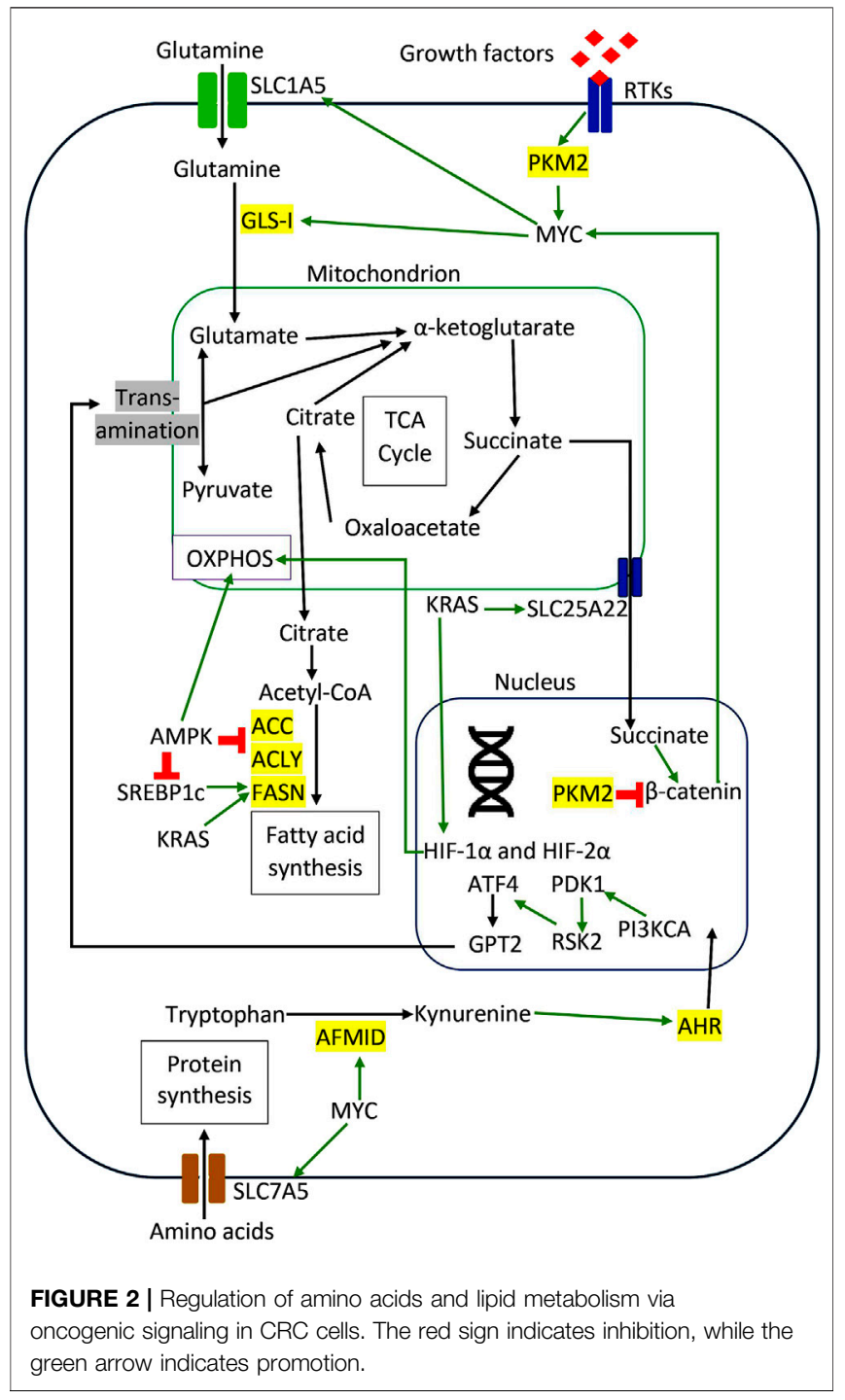

the expression of FASN, ACLY, ACC, and the transcriptional factor sterol regulating element-binding protein 1c (SREBP1c), resulting in de novo synthesis inhibition and reduced cell viability in CRC cells (Wang et al., 2021).

\section{SIGNALING PATHWAYS IN TRYPTOPHAN METABOLISM}

There are many other types of amino acid metabolism in cancer cells. Tryptophan (Trp) is an essential amino acid for protein synthesis, and it is the least abundant amino acid in most proteins (Adams et al., 2012). Venkateswaran et al. have presented a comprehensive work on the tryptophan metabolism in CRC cells. They discovered that CRC cells increase the tryptophan uptake and metabolism compared to normal colonic cells and tissues (Venkateswaran et al., 2019). Similarly, CRC cells were more sensitive to tryptophan depletion than their normal counterpart (Venkateswaran et al., 2019). Tryptophan can be metabolized in three different pathways (Blanco and Blanco, 2017a). Firstly it is incorporated into newly synthesized proteins (Blanco and Blanco, 2017a). Secondly, it enters the serotonin pathway to produce serotonin and melatonin (Blanco and Blanco, 2017a). Lastly, tryptophan enters the kynurenine pathway to generate kynurenine (Kyn), a biologically active metabolite (Van der Leek et al., 2017). The proto-oncogene c-MYC activates the kynurenine pathway in CRC cells by promoting the transcription of the tryptophan importers SLC1A5 and SLC7A5 and the tryptophan metabolizing enzyme arylformamidase AFMID (Venkateswaran et al., 2019). In the kynurenine pathway, tryptophan is metabolized by one of the three enzymes: indoleamine 2,3-dioxygenasel (IDO1), indoleamine 2,3dioxygenase2 (IDO2), and tryptophan 2,3-dioxygenase 2 (TDO2) to generate $\mathrm{N}$-formyl kynurenine, which is converted into kynurenine by AFMID (Van der Leek et al., 2017). Previously, IDO1 expression correlates with impaired immune response, hepatic metastases, and poor clinical outcomes in CRC (Brandacher et al., 2006). IDO1 and kynurenine pathway metabolites activate PI3K-AKT signaling to promote nuclear translocation of $\beta$-catenin, enhancing cancer cell proliferation and inhibit apoptosis in CRC cells. (Thaker et al., 2013; Bishnupuri et al., 2019). SLC7A5, SLC1A5, and AFMID were upregulated in CRC clinical samples with the increased level of kynurenine (Venkateswaran et al., 2019). Kynurenine functions as an oncometabolite to activate the nuclear translocation of the transcription factor AHR (aryl hydrocarbon receptor), which regulates target genes associated with proliferation in CRC cells (Venkateswaran and Conacci-Sorrell, 2020). Figure 2 illustrates the regulation of amino acids and lipid metabolism via oncogenic signaling in CRC cells. Table 1 summarizes the main contributions of previous studies to the field of CRC metabolism, as discussed earlier.

\section{METABOLIC REPROGRAMMING IN COLORECTAL CANCER CANCER STEM CELLS}

Cancer stem cells (CSCs) represent a subpopulation of tumor cells with self-renewal and multi-lineage differentiation to regulate tumor growth and heterogeneity (Walcher et al., 2020). CSCs have been identified as the critical regulator of cancer progression in various solid tumors, including CRC, driving cancer initiation and cancer relapse (Ayob and Ramasamy, 2018). CSCs undergo metabolic adaptation to support their stemness properties and promote tumor development (Batlle and Clevers, 2017). In CRC, the metabolic reprogramming in CSCs is closely associated with the expression of signaling molecules and stem cell markers. CRC CSCs are known to express specific stem cell markers, such as CD133, $\mathrm{CD} 44$, leucine-rich repeat-containing $\mathrm{G}$ protein-coupled receptor 5 (LGR5), and epithelial cell adhesion molecule (EpCAM) (Munro et al., 2018). CD133 is a well-characterized marker in CRC CSCs, while CD133(+) cells can initiate tumor formation in the animal model (Wang et al., 2012; Li, 2013). Based on the 
TABLE 1 | Summarizes the main contributions of previous studies to the field of CRC metabolism.

\begin{tabular}{|c|c|c|c|}
\hline $\begin{array}{l}\text { Molecule/Signaling } \\
\text { pathway involved }\end{array}$ & Target enzyme/Effector & Function & Reference \\
\hline \multicolumn{4}{|l|}{ The Warburg Effect } \\
\hline EGFR/Akt & HKII & Inhibits glycolysis upon suppression by xanthohumol & Liu et al. (2019) \\
\hline GLCC1/C-MYC & LDHA & Promotes CRC progression and glucose metabolism & Tang et al. (2019) \\
\hline NDRG2/ $\beta$-catenin/c-MYC & GLUT1, HKII, PKM2, and LDHA & Inhibits glycolysis through c-MYC suppression & Xu et al. (2015) \\
\hline $\begin{array}{l}\text { CD36/GPC } 4 / \beta \text {-catenin/ } \\
\text { c-MYC }\end{array}$ & Multiple glycolytic genes & Inhibits glycolysis and tumorigenesis in CRC cells & Fang et al. (2019) \\
\hline CD44 & PKM2 & Promotes Warburg effect & Tamada et al. (2012) \\
\hline $\begin{array}{l}\text { Nuclear PKM2/HIF1a/ } \\
\beta \text {-catenin }\end{array}$ & Multiple glycolytic genes & Promotes glycolysis and autoregulation of PKM2 & $\begin{array}{l}\text { Luo et al. (2011), Yang et al. (2012), } \\
\text { Prigione et al. (2014) }\end{array}$ \\
\hline IL-6/STAT3/c-MYC & GLUT1, LDH & Increases glucose uptake and lactate production & Qu et al. (2017) \\
\hline JAK2/STAT3 & $\mathrm{HKII}$ & Inhibits glycolysis and lactate production & Li et al. (2020c) \\
\hline C-MYC & HKII & $\begin{array}{l}\text { Inhibits glycolysis and induce apoptosis in CRC cells upon } \\
\text { dioscin stimulation }\end{array}$ & Wu et al. (2020) \\
\hline PLK3/HSP90/STAT3 & HKII & Inhibits glucose metabolism & Ou et al. (2019) \\
\hline Sam68 & PKM1/PKM2 & Upregulates glycolysis and proliferation in CRC cells & Zhao et al. (2020a) \\
\hline $\begin{array}{l}\text { miR-124/c-MYC/E2F1/ } \\
\text { STAT3/PTB1 }\end{array}$ & $\mathrm{PKM} 1 / \mathrm{PKM} 2$ & Promotes PKM2 production and glycolysis & Taniguchi et al. (2015b) \\
\hline $\begin{array}{l}\text { miR-124/DDX6/c-MYC/ } \\
\text { PTB1 }\end{array}$ & PKM2 & Promotes Warburg effect & Taniguchi et al. (2015a) \\
\hline Wnt/ $\beta$-catenin/PKM2 & $\begin{array}{l}\text { LDHA, GLUT1, PFK1-M, and } \\
\text { PFKBP1 }\end{array}$ & Promotes Warburg effect & Cha et al. (2021) \\
\hline \multicolumn{4}{|l|}{ Glutaminolysis } \\
\hline EGFR/PKM2/c-MYC/IRES & GLS-I & Promotes glutaminolysis & Li et al. (2020a) \\
\hline KRAS mutation & Multiple glutaminolysis enzymes & $\begin{array}{l}\text { Regulates glutaminolysis, mitochondrial respiration, and } \\
\text { ROS production }\end{array}$ & $\begin{array}{l}\text { Weinberg et al. (2010), Hutton et al. } \\
\text { (2016) }\end{array}$ \\
\hline KRAS mutation & $\begin{array}{l}\text { Mitochondrial glutamine } \\
\text { transporter SLC25A22 }\end{array}$ & $\begin{array}{l}\text { Regulates glutamine metabolism, Wnt signaling, cancer } \\
\text { stemness, and drug resistance }\end{array}$ & Wong et al. (2016) \\
\hline $\begin{array}{l}\text { Nuclear PKM2/miR-200/ } \\
\beta \text {-catenin/C-MYC }\end{array}$ & Mitochondrial glutaminase & Promotes glutaminolysis & Wu et al. (2014). \\
\hline PI3K/PDK1/RSK2/ATF4 & GPT2 & $\begin{array}{l}\text { Increases glutamine metabolism to replenish the TCA cycle } \\
\text { and generate ATP }\end{array}$ & Hao et al. (2016) \\
\hline \multicolumn{4}{|l|}{$\begin{array}{l}\text { Oxidative Phosphorylation } \\
\text { (OXPHOS) }\end{array}$} \\
\hline KRAS mutations & $\mathrm{HIF}-1 \alpha$ and $\mathrm{HIF}-2 \alpha$ & $\begin{array}{l}\text { Increases mitochondrial respiration and reduces ROS } \\
\text { production }\end{array}$ & Chun et al. (2010) \\
\hline \multicolumn{4}{|l|}{ Lipid Metabolism } \\
\hline $\begin{array}{l}\text { AMPK } \\
\text { KRAS mutations }\end{array}$ & $\begin{array}{l}\text { FASN, ACLY, ACC, SREBP1C } \\
\text { FASN }\end{array}$ & $\begin{array}{l}\text { Inhibits fatty acid synthesis and reduces cell viability } \\
\text { Upregulates fatty acid } \beta \text {-oxidation }\end{array}$ & $\begin{array}{l}\text { Wang et al. (2021). } \\
\text { Zaytseva et al. (2015) }\end{array}$ \\
\hline \multicolumn{4}{|l|}{ Tryptophan Metabolism } \\
\hline C-MYC & SLC7A5, SLC1A5, AFMID & $\begin{array}{l}\text { Upregulates tryptophan metabolism via the kynurenine } \\
\text { pathway }\end{array}$ & Venkateswaran et al. (2019) \\
\hline
\end{tabular}

analysis of microarray data from the GEO database, which included sorted CD133(+) and CD133(-) subfractions of CRC CSCs, Chen et al. revealed that genes involved in glycolysis, TCA cycle, and one-carbon metabolism were upregulated in CD133(+) cells. However, at the same time, genes involved in fatty acid biosynthesis were downregulated (Chen et al., 2014). Their findings suggest that CD133(+) CRC CSCs upregulates glycolysis for energy production while suppressing fatty acid biosynthesis.

CD133(+) CRC CSCs also exhibit an altered lipid metabolism as compared to non-CSC counterparts. By using transmission electron microscopy imaging and flow cytometry analysis, Tirinato et al. discovered that CD133(+) CSCs contain more lipid droplets in the cytoplasm as compared to CD133(-) cells (Tirinato et al., 2015). The authors also observed a similar result by stratifying cells based on Wnt/ $\beta$-catenin activity instead of CD133 expression level, suggesting a possible correlation between CD133 and Wnt signaling to modulate the lipid metabolism in CRC stem cells (Tirinato et al., 2015). Functionally, CRC stem cells with high lipid droplet content demonstrated a higher in vitro sphere-forming ability and a more significant tumor formation upon subcutaneous injection in the animal model. The 


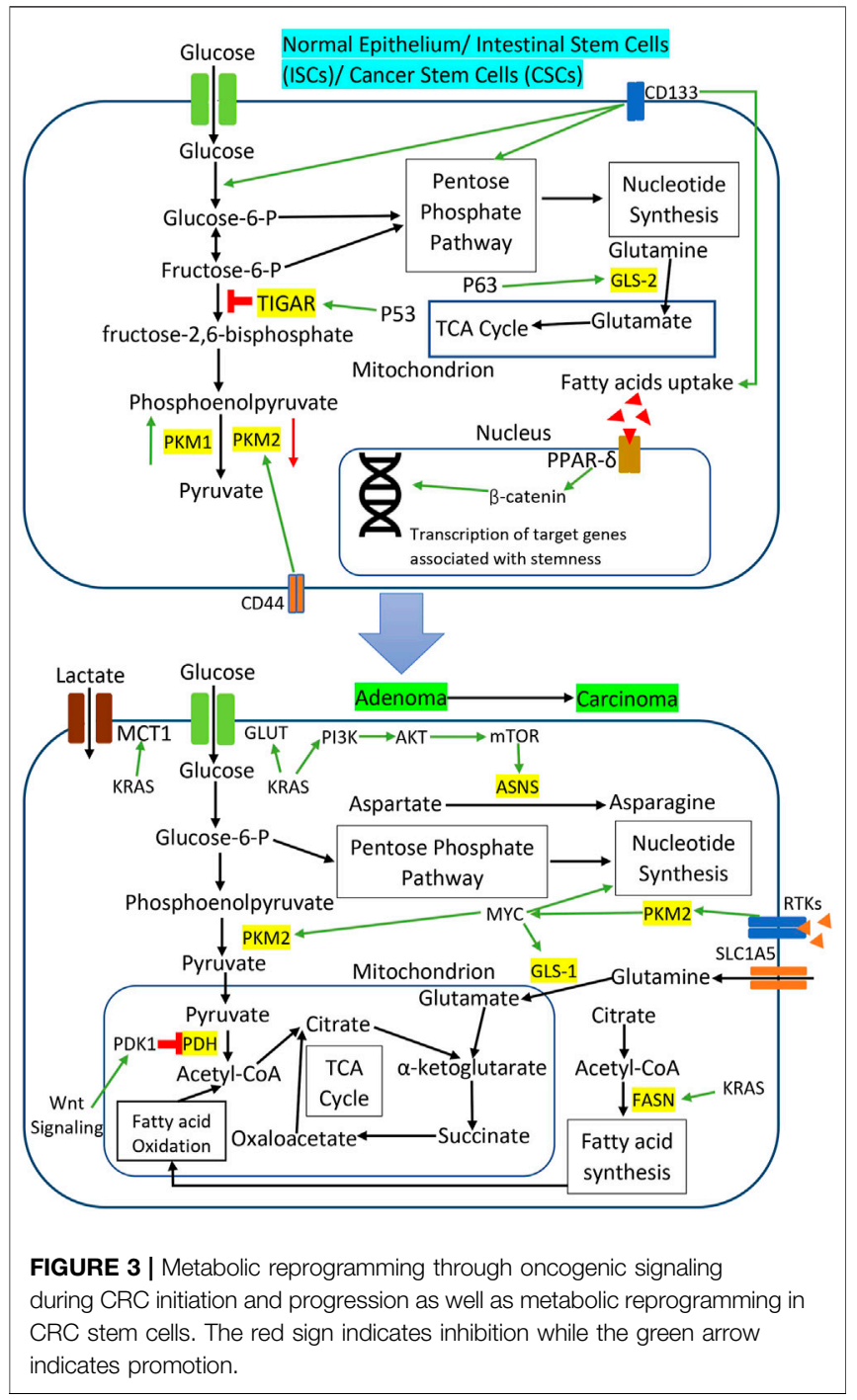

reprogramming of lipid metabolism could be essential in promoting the tumorigenesis of CRC stem cells.

CD44 is another stem cell marker in CRC CSCs, which also acts as the cell surface glycoprotein to participate in cellular interactions and cellular migration (Morath et al., 2016; Senbanjo and Chellaiah, 2017). CD44 transcription is activated by $\beta$-catenin/Wnt signaling, while its overexpression is frequently associated with the early transformation of colorectal adenoma to carcinoma (Orian-Rousseau, 2015). Knockdown of CD44 in CRC cell line HCT116 decreased the glucose uptake and consumption by downregulating PKM2 activity and lactate production (Tamada et al., 2012). Simultaneously, CD44 ablation in HCT116 cells also reduced glucose utilization by the pentose phosphate pathway (Tamada et al., 2012). CD44 could play an essential role in the metabolic reprogramming of CRC stem cells by inducing the switching of glucose metabolism from OXPHOS to glycolysis and pentose phosphate pathways. Moreover, CD44(+) CRC CSCs express a higher glutamine level as compared with the CD44(-) counterparts, but the actual interaction between CD44 and glutamine metabolism is yet to be investigated (Huang et al., 2016). The increased glutamine in CD44(+) CSCs can support CRC energy production to promote cell survival, growth, and proliferation.

The transcription factor $\mathrm{p} 63$ is a member of the p53 transcription factor family, which has been expressed in CRC CSCs, while p63 mutation is associated with poor clinical prognosis among CRC patients (Pignon et al., 2013; Bahnassy et al., 2014). Through its N-terminal trans-activator domain, p63 activates mitochondrial glutaminase 2 (GLS2) in CRC cells to catalyze the conversion of glutamine into glutamate and a-ketoglutarate for subsequent ATP production via the TCA cycle (Giacobbe et al., 2013). Glutamate is an essential precursor of glutathione, which is the primary ROS intracellular scavenger. The authors observed that GLS2 was significantly upregulated in CRC tissue samples with decreased cellular levels of ROS, suggesting that p63/GLS2 axis could be essential to protect CRC cells against oxidative stresses (Giacobbe et al., 2013). Furthermore, p63 overexpression in CRC is also associated with the upregulation of glycolysis in CSC cultures, implicating that p63 could be a crucial glycolytic regulator in CRC stem cells (D’Aguanno et al., 2014).

\section{CROSSTALK BETWEEN ONCOGENIC SIGNALING AND METABOLIC PATHWAYS IN COLORECTAL CANCER PROGRESSION}

CRC pathogenesis is a multi-step transformation that involves multiple genetic alterations to promote cancer initiation and progression. The activation of oncogenic signaling is essential to drive the stepwise progression of CRC via metabolic reprogramming to promote cancer cell survival, proliferation, epithelial-mesenchymal transition (EMT), angiogenesis, invasion, and migration. Metabolic reprogramming plays a vital role in different stages of CRC progression, from the early transformation of normal epithelial cells into the entire adenoma-carcinoma sequence. $\mathrm{Lgr}^{+}{ }^{+}$intestinal stem cells (ISCs) are the progenitors of secretory cells and enterocytes that produce mature intestinal epithelial cells, so ISCs are also the cancer stem cells for CRC, as shown by lineage tracing studies (Barker et al., 2009; Merlos-Suarez et al., 2011; Kemper et al., 2012). TIGAR (TP53-inducible glycolysis and apoptosis regulator) is transcriptionally activated by $\mathrm{p} 53$ tumor suppressor protein to decrease the intracellular levels of fructose-2,6-bisphosphate (Fru-2,6-BP) and downregulate the glycolytic pathway (Bensaad et al., 2006). Subsequently, TIGAR diverts the glucose metabolism towards the pentose phosphate pathway (PPP) to produce NADPH for antioxidant function and ribose-5-phosphate for nucleotide synthesis ( $\mathrm{Li}$ and $\mathrm{Jogl}$, 2009). Eric et al. reported that TIGAR was required for injuryinduced regeneration in ISCs, by promoting PPP to generate NADPH and ribose-5-phosphate rapidly (Cheung et al., 2013). TIGAR was upregulated in human CRC cell lines and tumors regardless of p53 status, while the authors also observed that TIGAR promoted adenoma formation in a mouse model of intestinal cancer (Cheung et al., 2013). All this evidence suggests that TIGAR is essential to support cell proliferation by reprogramming glucose metabolism during CRC initiation. 
TABLE 2 | List of small molecule inhibitors and monoclonal antibodies for CRC therapy in clinical trials or approved by the FDA.

\begin{tabular}{|c|c|c|c|}
\hline Drug & Target & Clinical stage & Reference \\
\hline \multicolumn{4}{|c|}{ Small Molecule Inhibitors } \\
\hline Afatinib & EGFR & Phase II & De Pauw et al. (2016) \\
\hline Alpelisib & PI3K & Phase II & Tabernero et al. (2016) \\
\hline Cobimetinib & MAPK & Phase II & Klute et al. (2020) \\
\hline Dabrafenib & BRAF & Phase ॥ & Corcoran et al. (2015) \\
\hline Dasatinib & Src & Phase ॥ & Scott et al. (2017) \\
\hline Encorafenib & BRAF & FDA approval in 2020 & Kopetz et al. (2019) \\
\hline Enzastaurin & AKT & Phase II & Wolff et al. (2012) \\
\hline Erlotinib & EGFR & Phase III & Hagman et al. (2016) \\
\hline Everolimus & mTOR & Phase II & $\mathrm{Ng}$ et al. (2013) \\
\hline Gedatolisib & $\mathrm{PI} 3 \mathrm{~K} / \mathrm{mTOR}$ & Phase ॥ & Wainberg et al. (2017) \\
\hline Gefitinib & EGFR & Phase II & Troiani et al. (2016) \\
\hline Mk-2206 & AKT & Phase II & Do et al. (2015) \\
\hline Napabucasin & STAT3 & Phase III & Jonker et al. (2018) \\
\hline Niclosamide & STAT3 & Phase I & Burock et al. (2018) \\
\hline Pelitinib & EGFR & Phase ॥ & To et al. (2020) \\
\hline Regorafenib & VEGFR, KIT, PDGFR, RET, TIE2,EPH2A & FDA approval in 2012 & Papadopoulos and Lennartsson, (2018) \\
\hline Sonolisib & $\mathrm{PI} 3 \mathrm{~K}$ & Phase II & Bowles et al. (2016) \\
\hline Trametinib & BRAF & Phase II & Corcoran et al. (2015) \\
\hline Temsirolimus & mTOR & Phase II & Spindler et al. (2013) \\
\hline Vemurafenib & BRAF & Phase ॥ & Klute et al. (2020) \\
\hline \multicolumn{4}{|c|}{ Monoclonal Antibodies } \\
\hline Bevacizumab & VEGF-A & FDA approval in 2004 & Rosen et al. (2017) \\
\hline Cetuximab & EGFR & FDA approval in 2004 & Bokemeyer et al. (2012) \\
\hline Panitumumab & EGFR & FDA approval in 2006 & Hocking and Price, (2014) \\
\hline Pertuzumab & HER2 & Phase II & Meric-Bernstam et al. (2019) \\
\hline Ramucirumab & VEGFR2 & FDA approval in 2015 & Verdaguer et al. (2016) \\
\hline Rilotumumab & HGF & Phase \|I & Van Cutsem et al. (2014) \\
\hline Trastuzumab & HER2 & Phase ॥ & Meric-Bernstam et al. (2019) \\
\hline
\end{tabular}

Additionally, reprogramming of lipid metabolism is also associated with CRC initiation and maintenance of ISCs. Prolonged high-fat diet (HFD) in mice activates PPAR- $\delta$ (peroxisome proliferator-activated receptor-delta) in ISCs to upregulate a subset of $\beta$-catenin target genes associated with cancer cell stemness (Beyaz et al., 2016). Consequently, ISCs proliferate rapidly and increase adenoma formation in a mouse model of APC loss-induced intestinal tumorigenesis (Beyaz et al., 2016). Kim et al. reported that loss of PKM2 in Lgr5(+) ISCs promoted inflammation-associated CRC in the mouse model, while a similar result was also reported in the APC-driven colon cancer mouse model (Lau et al., 2017; Kim et al., 2019). These studies suggest that PKM2 expression is not required for CRC initiation, although PKM2 overexpression was reported in advanced stages of CRC (Lau et al., 2017). The downregulation of PKM2 also significantly led to the activation of PKM1, which may suggest a compensatory expression of PKM1 by deletion of PKM2 to support the metabolic requirement and proliferation of CRC cells (Kim et al., 2019). Meanwhile, Satoh et al. describe that c-MYC is responsible for inducing a global metabolic reprogramming in CRC, which starts from the adenoma stage and remains similar through all cancer stages (Satoh et al., 2017). c-MYC induces the upregulation of glycolysis and nucleotide metabolism to support the rapid proliferation of CRC cells during tumorigenesis (Satoh et al., 2017). Additionally, the protein kinase function of PKM2 activates c-MYC upon the signaling from RTKs (Li L. et al., 2020). The activated c-MYC also increases the glutamine uptake and metabolism in CRC cells by promoting the glutamine transporter SLC1A5 and glutaminase GLS-I (Li L. et al., 2020).

Accumulating evidence suggests that Wnt signaling and KRAS mutations induce metabolic reprogramming in the adenoma and carcinoma stage of CRC to support the energetic and biosynthetic requirements of rapidly proliferating CRC cells. Activation of Wnt signaling in CRC cell lines promotes glucose metabolism and lactate production by upregulating the transcription of pyruvate dehydrogenase kinase 1 (PDK1) and lactate transporter, MCT-1 (Pate et al., 2014; Sprowl-Tanio et al., 2016). Wnt signaling-induced PDK1 prevents pyruvate flux to mitochondrial respiration and indirectly promotes cancer proliferation and angiogenesis in xenograft CRC tumors in the mouse model (Pate et al., 2014). KRAS mutations in CRC also promote tumor growth and cancer progression by rewiring glucose, amino acids, and lipid metabolism. KRAS mutations increase the glucose uptake in CRC cells via the upregulation of GLUT1 to generate more glycolytic intermediates for the utilization in different metabolic pathways in tumor expansion (Kawada et al., 2012; Iwamoto et al., 2014). Toda et al. observed that KRAS mutation altered the amino acid metabolism in CRC cells by reducing aspartate level and increasing asparagine level to 
TABLE 3 | List of potential metabolic inhibitors that target CRC cells.

\begin{tabular}{|c|c|c|c|}
\hline Compound & Target molecule/pathway & Function & Reference \\
\hline 2-DG & Glycolytic enzymes & $\begin{array}{l}\text { Inhibition of glycolysis with reduction of tumor invasion and } \\
\text { metastasis }\end{array}$ & Park et al. (2017), Xiang et al. (2019) \\
\hline DON & $\begin{array}{l}\text { Multiple glutamine-utilizing } \\
\text { enzymes }\end{array}$ & Inhibition of glutaminolysis and induction of cellular ROS & $\begin{array}{l}\text { Lemberg et al. (2018); Schcolnik-Cabrera et al. } \\
\text { (2020) }\end{array}$ \\
\hline AZD3965 & MCT1 & $\begin{array}{l}\text { Inhibition of lactate transport, glycolysis, and lipid } \\
\text { biosynthesis }\end{array}$ & Beloueche-Babari et al. (2020) \\
\hline CB839 & GLS1 & Inhibition of glutaminolysis & Zhao et al. (2020b), Cohen et al. (2020) \\
\hline $\begin{array}{l}\text { Cerulenin plus } \\
\text { oxaliplatin }\end{array}$ & FASN & $\begin{array}{l}\text { Inhibition of proliferation and metastasis with induction of } \\
\text { apoptosis }\end{array}$ & Murata et al. (2010); Shiragami et al. (2013) \\
\hline EGCG & FASN & Downregulation of STAT3 and reduced proliferation & Wang et al. (2021) \\
\hline GSK165 & ACLY & Activation of AKT signaling & Zhou et al. (2013) \\
\hline IDF-11774 & HIF1a & Inhibition of glycolysis and angiogenesis & Misale et al. (2012) \\
\hline L-Aspartate plus & ASNS and mTOR & Inhibition of asparagine biosynthesis & Toda et al. (2016) \\
\hline \multicolumn{4}{|l|}{ Rapac-MYCin } \\
\hline Luteolin & FASN & Modulation of Wnt/ $\beta$-catenin signaling & $\begin{array}{l}\text { Horinaka et al. (2005), Pandurangan and Esa } \\
\text { (2014), Yao et al. (2019b) }\end{array}$ \\
\hline Metformin & $\begin{array}{l}\text { Mitochondrial electron } \\
\text { transport complex I }\end{array}$ & AMPK activation and PKM2 inhibition & Zhang et al. (2011); Carr et al. (2016) \\
\hline Mito-Metformin & $\begin{array}{l}\text { Mitochondrial electron } \\
\text { transport complex I }\end{array}$ & ATP depletion & Hosono et al. (2010) \\
\hline Oxamate & LDHA & Inhibition of glycolysis & Yang et al. (2014b), Salgado-Garcia et al. (2021) \\
\hline R05126766 & RAF/MEK & Downregulation of GLUT1 & Wu et al. (2015) \\
\hline TVB-3166 & FASN & Inhibition of de novo palmitate synthesis & Ventura et al. (2015) \\
\hline TVB-3664 & FASN and CD36 & $\begin{array}{l}\text { Suppression of lipid metabolism and transport, Modulation } \\
\text { of AKT and ERK1/2 signaling }\end{array}$ & Zaytseva et al. (2018) \\
\hline Vitamin C & EGFR/MAPK & $\begin{array}{l}\text { Decreased phosphorylation of PKM2 and reduced GLUT1 } \\
\text { expression }\end{array}$ & Aguilera et al. (2016) \\
\hline WZB117 & GLUT1 & Downregulation of GLUT1 & Misale et al. (2012) \\
\hline $\begin{array}{l}\text { WZB117 plus } \\
\text { Ficlatuzumab }\end{array}$ & GLUT1 and HGF & Inhibition of glucose uptake and blocking HGF activity & Song et al. (2017) \\
\hline
\end{tabular}

maintain cell viability and tumor growth under the glutaminedepleted condition (Toda et al., 2016). Mutant KRAS upregulated asparagine synthetase (ASNS) expression through PI3K/AKT/ mTOR signaling to increase the asparagine biosynthesis and promote CRC cell growth (Toda et al., 2016). Meanwhile, fatty acid synthase (FASN) is overexpressed in KRAS mutant CRC cell lines to support cellular respiration via lipid oxidation and subsequently provide a survival advantage under metabolic stress (Zaytseva et al., 2015). Figure 3 illustrates specific metabolic pathways rewired through oncogenic signaling during CRC initiation and progression, as well as metabolic reprogramming in CRC stem cells.

\section{TARGETING COLORECTAL CANCER METABOLISM}

As discussed above, metabolic reprogramming is critical in the CRC tumorigenesis to support cancer initiation, proliferation, invasion, and metastasis. The first line of treatment for early-stage CRC patients (stage I and II) is surgical resection, while chemotherapy and radiotherapy are mostly recommended for late-stage II and above (Dekker et al., 2019). Chemotherapy for CRC patients usually includes the combination of chemotherapy agents, such as FOLFOX (5-FU, leucovorin, and oxaliplatin) or FOLFIRI (5-FU, leucovorin, and irinotecan), to maximize the treatment efficacy (Keum and Giovannucci, 2019). However, chemotherapy often comes with serious side effects, such as nausea, vomiting, loss of hair, and body weakness, which affect the life quality of CRC patients (Onyoh et al., 2019). Drug resistance becomes another difficulty in chemotherapy for CRC, as it quickly gives rise to cancer relapse and metastasis that significantly reduce the survival rate and prognosis among CRC patients (Rawla et al., 2019). Over the years, researchers have been looking into alternatives for chemotherapy in CRC management, possibly with more minor side effects and similar efficacy. Thus, targeting CRC metabolism could become another potential option for CRC therapy.

The advancement in the molecular biology of cancer has allowed researchers to identify the dysregulation of protein kinases as the effectors of signaling pathways in cancer development and progression. These relevant findings have led to pharmacological inhibitors that directly target protein kinases and signaling pathways in cancers to kill the cancer cells more effectively (Butti et al., 2018; Jiang and Ji, 2019). As protein kinases are the essential regulators of metabolic reprogramming, protein kinases inhibitors could be repurposed to target the CRC metabolism. In general, most of the inhibitors available can be grouped into two categories: small molecule intervention and antibody blocking (Lemmon and Schlessinger, 2010). Smallmolecule inhibitors can target the ATP-binding site of protein kinases specifically to inhibit phosphorylation, while monoclonal antibodies are developed to bind to the extracellular domain of protein kinases and suppress kinase-ligand interaction 
(Gaumann et al., 2016; Gan et al., 2017). Many of these inhibitors are being investigated in phase II clinical studies in CRC, while the US FDA has approved several drugs for targeted therapy in clinical application, as listed in Table 2. These small molecule inhibitors and monoclonal antibodies can be used as monotherapy or combined with conventional therapies to increase the therapeutic efficacy and cancer specificity (To et al., 2020; Hwang et al., 2021). For instance, cetuximab and panitumumab are monoclonal antibodies that target EGFR and can be used as monotherapy or combined with chemotherapy to treat patients with RAS wild-type metastatic CRC (Hayashi et al., 2017; Garcia-Foncillas et al., 2019).

Some natural compounds and synthetic agents have been discovered to target metabolic enzymes and signaling molecules directly. Consequently, these compounds can function as metabolic inhibitors which could potentially target CRC metabolism, as listed in Table 3. Some studies demonstrate that naturally derived metabolic inhibitors can be administered without side effects and are much safer than conventional chemotherapeutics (Pandurangan and Esa, 2014; Wang et al., 2021). Obesity and a high-fat diet are commonly associated with a higher risk of CRC, in which upregulation of lipid metabolic enzymes such as FASN and ACC often leads to CRC progression and metastasis through activation of oncogenic pathways including Wnt, PI3K/AKT, AMPK/mTOR. Thus, research on compound targeting enzymes involved in lipid metabolism could be promising in the future management of CRC cases. For example, luteolin (3,4,5,7-tetrahydroxyflavone) which is found in vegetables, fruits, and medicinal herbs, functions as a fatty acid synthase (FASN) inhibitor to modulate lipid metabolism in CRC cells via $\mathrm{Wnt} / \beta$-catenin signaling (Pandurangan and Esa, 2014). Luteolin can be orally administrated in a dosage of up to $500 \mathrm{mg}$ twice a day without side effects (Luo et al., 2017). Notably, the combination of metabolic inhibitors and chemotherapy drugs has been shown to enhance the therapeutic efficacy and reduce the toxicity simultaneously, which is promising for the future development of CRC therapy. For instance, a combination of glutaminase (GLS) inhibitor CB839 and 5-FU chemotherapy drug increases the anti-cancer effect on the xenograft growth of PIK3CA-mutant CRC cells without significant dose-limiting toxicity (Zhao Y. et al., 2020).

\section{REFERENCES}

Adams, S., Braidy, N., Bessede, A., Bessesde, A., Brew, B. J., Grant, R., et al. (2012). The Kynurenine Pathway in Brain Tumor Pathogenesis. Cancer Res. 72 (22), 5649-5657. doi:10.1158/0008-5472.CAN-12-0549

Aguilera, O., Muñoz-Sagastibelza, M., Torrejón, B., Borrero-Palacios, A., Del Puerto-Nevado, L., Martínez-Useros, J., et al. (2016). Vitamin C Uncouples the Warburg Metabolic Switch in KRAS Mutant colon Cancer. Oncotarget 7 (30), 47954-47965. doi:10.18632/oncotarget.10087

Akao, Y., Matsumoto, K., Ohguchi, K., Nakagawa, Y., and Yoshida, H. (2006). Human DEAD-Box/RNA Unwindase Rck/p54 Contributes to Maintenance of Cell Growth by Affecting Cell Cycle in Cultured Cells. Int. J. Oncol. 29 (1), 41-48. doi:10.3892/ijo.29.1.41

\section{CONCLUSION}

The reprogramming of cellular metabolism is vital in tumor development. Metabolic reprogramming constitutes an important cancer hallmark in CRC, which gives rise to the alteration in aerobic glycolysis, glutaminolysis, OXPHOS, and lipid metabolism. Numerous studies have demonstrated that oncogenic mutations and loss of tumor suppressor genes contribute to CRC cell metabolic reprogramming by modulating the downstream signaling pathways. Protein kinases, such as AKT and c-MYC, regulate the expression of metabolic enzymes at both transcriptional and translational levels. The crosstalk between oncogenic pathways and the metabolic pathways represents another new avenue to develop therapeutics for CRC. Small molecule inhibitors and monoclonal antibodies currently available could be repurposed to target CRC metabolism by regulating protein kinases and signaling pathways involved. The discovery of metabolic inhibitors could become the alternative to the current treatment options, such as chemotherapy and radiotherapy, that are associated with severe side effects. The development of therapeutic based on CRC metabolism is challenging when most of the research data is generated from cell line models. Given the complexity of the tumor microenvironment and the heterogeneity of actual tumors, many questions regarding dosage safety and the therapeutic efficacy in clinical trials are waiting to be answered.

\section{AUTHOR CONTRIBUTIONS}

Conceptualization, $\mathrm{KWH}$ and $\mathrm{RN}$; writing-original draft preparation, KWH; writing-review and editing, SA, IO, and RN. All authors have read and agreed to the published version of the manuscript.

\section{ACKNOWLEDGMENTS}

The authors would like to thank Jeffrey Cheah School of Medicine \& Health Sciences, Monash University Malaysia for providing the research facilities and support to conduct this study. KWH would like to thank Monash University Malaysia for awarding the Campus Merit Scholarship to support his study.

Akao, Y. (2009). A Role of DEAD-Box RNA Helicase Rck/p54 in Cancer Cells. Cdth 4 (1), 29-37. doi:10.2174/157488509787081912

Arora, L., Kumar, A. P., Arfuso, F., Chng, W. J., and Sethi, G. (2018). The Role of Signal Transducer and Activator of Transcription 3 (STAT3) and its Targeted Inhibition in Hematological Malignancies. Cancers (Basel) 10 (9), 327. doi:10.3390/cancers 10090327

Asante, I., Chui, D., Pei, H., Zhou, E., De Giovanni, C., Conti, D., et al. (2019). Alterations in Folate-dependent One-Carbon Metabolism as colon Cell Transition from normal to Cancerous. J. Nutr. Biochem. 69, 1-9. doi:10.1016/j.jnutbio.2019.02.008

Ayob, A. Z., and Ramasamy, T. S. (2018). Cancer Stem Cells as Key Drivers of Tumour Progression. J. Biomed. Sci. 25 (1), 20. doi:10.1186/s12929-018-0426-4 Bahnassy, A. A., Zekri, A. R., Salem, S. E., Abou-Bakr, A. A., Sakr, M. A., AbdelSamiaa, A. G., et al. (2014). Differential Expression of P53 Family Proteins in 
Colorectal Adenomas and Carcinomas: Prognostic and Predictive Values. Histol. Histopathol 29 (2), 207-216. doi:10.14670/hh-29.207

Barker, N., Ridgway, R. A., van Es, J. H., van de Wetering, M., Begthel, H., van den Born, M., et al. (2009). Crypt Stem Cells as the Cells-Of-Origin of Intestinal Cancer. Nature 457 (7229), 608-611. doi:10.1038/nature07602

Barr, F. A., Silljé, H. H., and Nigg, E. A. (2004). Polo-like Kinases and the Orchestration of Cell Division. Nat. Rev. Mol. Cell Biol 5 (6), 429-440. doi:10.1038/nrm1401

Batlle, E., and Clevers, H. (2017). Cancer Stem Cells Revisited. Nat. Med. 23 (10), 1124-1134. doi:10.1038/nm.4409

Beloueche-Babari, M., Casals Galobart, T., Delgado-Goni, T., Wantuch, S., Parkes, H. G., Tandy, D., et al. (2020). Monocarboxylate Transporter 1 Blockade with AZD3965 Inhibits Lipid Biosynthesis and Increases Tumour Immune Cell Infiltration. Br. J. Cancer 122 (6), 895-903. doi:10.1038/s41416-019-0717-x

Bensaad, K., Tsuruta, A., Selak, M. A., Vidal, M. N., Nakano, K., Bartrons, R., et al. (2006). TIGAR, a P53-Inducible Regulator of Glycolysis and Apoptosis. Cell 126 (1), 107-120. doi:10.1016/j.cell.2006.05.036

Beyaz, S., Mana, M. D., Roper, J., Kedrin, D., Saadatpour, A., Hong, S. J., et al. (2016). High-fat Diet Enhances Stemness and Tumorigenicity of Intestinal Progenitors. Nature 531 (7592), 53-58. doi:10.1038/nature17173

Bishnupuri, K. S., Alvarado, D. M., Khouri, A. N., Shabsovich, M., Chen, B., Dieckgraefe, B. K., et al. (2019). Ido1 and Kynurenine Pathway Metabolites Activate PI3K-Akt Signaling in the Neoplastic Colon Epithelium to Promote Cancer Cell Proliferation and Inhibit Apoptosis. Cancer Res. 79 (6), 1138-1150. doi:10.1158/0008-5472.CAN-18-0668

Blanco, A., and Blanco, G. (2017a). "Amino Acid Metabolism," in Medical Biochemistry. Editors A. Blanco and G. Blanco (Academic Press), 367-399. doi:10.1016/b978-0-12-803550-4.00016-1

Blanco, A., and Blanco, G. (2017b). "Carbohydrate Metabolism," in Medical Biochemistry. Editors A. Blanco and G. Blanco (Academic Press), 283-323. doi:10.1016/b978-0-12-803550-4.00014-8

Blanco, A., and Blanco, G. (2017c). "Integration and Regulation of Metabolism," in Medical Biochemistry. Editors A. Blanco and G. Blanco (Academic Press), 425-445. doi:10.1016/b978-0-12-803550-4.00019-7

Blanco, A., and Blanco, G. (2017d). "Lipid Metabolism," in Medical Biochemistry. Editors A. Blanco and G. Blanco (Academic Press), 325-365. doi:10.1016/b9780-12-803550-4.00015-x

Bokemeyer, C., Van Cutsem, E., Rougier, P., Ciardiello, F., Heeger, S., Schlichting, M., et al. (2012). Addition of Cetuximab to Chemotherapy as First-Line Treatment for KRAS Wild-type Metastatic Colorectal Cancer: Pooled Analysis of the CRYSTAL and OPUS Randomised Clinical Trials. Eur. J. Cancer 48 (10), 1466-1475. doi:10.1016/j.ejca.2012.02.057

Bowles, D. W., Kochenderfer, M., Cohn, A., Sideris, L., Nguyen, N., ClineBurkhardt, V., et al. (2016). A Randomized, Phase II Trial of Cetuximab with or without PX-866, an Irreversible Oral Phosphatidylinositol 3-Kinase Inhibitor, in Patients with Metastatic Colorectal Carcinoma. Clin. Colorectal Cancer 15 (4), 337-e2. e332. doi:10.1016/j.clcc.2016.03.004

Brandacher, G., Perathoner, A., Ladurner, R., Schneeberger, S., Obrist, P., Winkler, C., et al. (2006). Prognostic Value of Indoleamine 2,3-dioxygenase Expression in Colorectal Cancer: Effect on Tumor-Infiltrating T Cells. Clin. Cancer Res. 12 (4), 1144-1151. doi:10.1158/1078-0432.CCR-05-1966

Broecker-Preuss, M., Becher-Boveleth, N., Bockisch, A., Dührsen, U., and Müller, S. (2017). Regulation of Glucose Uptake in Lymphoma Cell Lines by C-MYC- and PI3K-dependent Signaling Pathways and Impact of Glycolytic Pathways on Cell Viability. J. Transl Med. 15 (1), 158. doi:10.1186/s12967-017-1258-9

Brown, R. E., Short, S. P., and Williams, C. S. (2018). Colorectal Cancer and Metabolism. Curr. Colorectal Cancer Rep. 14 (6), 226-241. doi:10.1007/s11888018-0420-y

Burock, S., Daum, S., Keilholz, U., Neumann, K., Walther, W., and Stein, U. (2018). Phase II Trial to Investigate the Safety and Efficacy of Orally Applied Niclosamide in Patients with Metachronous or Sychronous Metastases of a Colorectal Cancer Progressing after Therapy: the NIKOLO Trial. BMC Cancer 18 (1), 297. doi:10.1186/s12885-018-4197-9

Butti, R., Das, S., Gunasekaran, V. P., Yadav, A. S., Kumar, D., and Kundu, G. C. (2018). Receptor Tyrosine Kinases (RTKs) in Breast Cancer: Signaling, Therapeutic Implications and Challenges. Mol. Cancer 17 (1), 34. doi:10.1186/s12943-018-0797-x
Cai, J., Chen, Z., Wang, J., Wang, J., Chen, X., Liang, L., et al. (2019). circHECTD1 Facilitates Glutaminolysis to Promote Gastric Cancer Progression by Targeting miR-1256 and Activating $\beta$-catenin/c-Myc Signaling. Cell Death Dis 10 (8), 576. doi:10.1038/s41419-019-1814-8

Cairns, J., Fridley, B. L., Jenkins, G. D., Zhuang, Y., Yu, J., and Wang, L. (2018). Differential Roles of ERRFI1 in EGFR and AKT Pathway Regulation Affect Cancer Proliferation. EMBO Rep. 19 (3), e44767. doi:10.15252/embr.201744767

Cantor, J. R., and Sabatini, D. M. (2012). Cancer Cell Metabolism: One Hallmark, many Faces. Cancer Discov. 2 (10), 881-898. doi:10.1158/2159-8290.CD-120345

Cao, J., Ma, J., Sun, L., Li, J., Qin, T., Zhou, C., et al. (2018). Targeting Glypican-4 Overcomes 5-FU Resistance and Attenuates Stem Cell-like Properties via Suppression of Wnt/ $\beta$-Catenin Pathway in Pancreatic Cancer Cells. J. Cell Biochem 119 (11), 9498-9512. doi:10.1002/jcb.27266

Carr, R. M., Qiao, G., Qin, J., Jayaraman, S., Prabhakar, B. S., and Maker, A. V. (2016). Targeting the Metabolic Pathway of Human colon Cancer Overcomes Resistance to TRAIL-Induced Apoptosis. Cell Death Discov 2 (1), 16067. doi:10.1038/cddiscovery.2016.67

Casciano, J. C., Perry, C., Cohen-Nowak, A. J., Miller, K. D., Vande Voorde, J., Zhang, Q., et al. (2020). MYC Regulates Fatty Acid Metabolism through a Multigenic Program in Claudin-Low Triple Negative Breast Cancer. Br. J. Cancer 122 (6), 868-884. doi:10.1038/s41416-019-0711-3

Cha, P. H., Hwang, J. H., Kwak, D. K., Koh, E., Kim, K. S., and Choi, K. Y. (2021). APC Loss Induces Warburg Effect via Increased PKM2 Transcription in Colorectal Cancer. Br. J. Cancer 124 (3), 634-644. doi:10.1038/s41416-02001118-7

Chandrasekaran, B., Tyagi, A., Sharma, A. K., Cai, L., Ankem, M., and Damodaran, C. (2017). Molecular Insights: Suppression of EGFR and AKT Activation by a Small Molecule in Non-small Cell Lung Cancer. Genes Cancer 8 (9-10), 713-724. doi:10.18632/genesandcancer.154

Chen, C., Zhao, S., Karnad, A., and Freeman, J. W. (2018). The Biology and Role of CD44 in Cancer Progression: Therapeutic Implications. J. Hematol. Oncol. 11 (1), 64. doi:10.1186/s13045-018-0605-5

Chen, D., Pamu, S., Cui, Q., Chan, T. H., and Dou, Q. P. (2012). Novel Epigallocatechin Gallate (EGCG) Analogs Activate AMP-Activated Protein Kinase Pathway and Target Cancer Stem Cells. Bioorg. Med. Chem. 20 (9), 3031-3037. doi:10.1016/j.bmc.2012.03.002

Chen, K., Liu, X., Bu, P., Lin, C., Rakhilin, N., Locasale, J. W., et al. (2014). “A Metabolic Signature of colon Cancer Initiating Cells," in 36th Annual International Conference of the IEEE Engineering in Medicine and Biology Society, 4759-4762. doi:10.1109/embc.2014.6944688

Chen, M., Zhang, J., and Manley, J. L. (2010). Turning on a Fuel Switch of Cancer: hnRNP Proteins Regulate Alternative Splicing of Pyruvate Kinase mRNA. Cancer Res. 70 (22), 8977-8980. doi:10.1158/0008-5472.CAN-10-2513

Cheng, H. C., Qi, R. Z., Paudel, H., and Zhu, H. J. (2011). Regulation and Function of Protein Kinases and Phosphatases. Enzyme Res. 2011, 794089. doi:10.4061/ 2011/794089

Cheung, E. C., Athineos, D., Lee, P., Ridgway, R. A., Lambie, W., Nixon, C., et al. (2013). TIGAR Is Required for Efficient Intestinal Regeneration and Tumorigenesis. Dev. Cell 25 (5), 463-477. doi:10.1016/j.devcel.2013.05.001

Chiavarina, B., Whitaker-Menezes, D., Martinez-Outschoorn, U. E., Witkiewicz, A. K., Birbe, R., Howell, A., et al. (2011). Pyruvate Kinase Expression (PKM1 and PKM2) in Cancer-Associated Fibroblasts Drives Stromal Nutrient Production and Tumor Growth. Cancer Biol. Ther. 12 (12), 1101-1113. doi:10.4161/ cbt.12.12.18703

Cho, S. H., Park, Y. S., Kim, H. J., Kim, C. H., Lim, S. W., Huh, J. W., et al. (2012). CD44 Enhances the Epithelial-Mesenchymal Transition in Association with colon Cancer Invasion. Int. J. Oncol. 41 (1), 211-218. doi:10.3892/ijo.2012.1453

Chun, S. Y., Johnson, C., Washburn, J. G., Cruz-Correa, M. R., Dang, D. T., and Dang, L. H. (2010). Oncogenic KRAS Modulates Mitochondrial Metabolism in Human colon Cancer Cells by Inducing HIF- $1 \alpha$ and HIF-2 $\alpha$ Target Genes. Mol. Cancer 9, 293. doi:10.1186/1476-4598-9-293

Ciscato, F., Filadi, R., Masgras, I., Pizzi, M., Marin, O., Damiano, N., et al. (2020). Hexokinase 2 Displacement from Mitochondria-Associated Membranes Prompts Ca2+ -dependent Death of Cancer Cells. EMBO Rep. 21 (7), e49117. doi:10.15252/embr.201949117

Clower, C. V., Chatterjee, D., Wang, Z., Cantley, L. C., Vander Heiden, M. G., and Krainer, A. R. (2010). The Alternative Splicing Repressors hnRNP A1/A2 and 
PTB Influence Pyruvate Kinase Isoform Expression and Cell Metabolism. Proc. Natl. Acad. Sci. U S A. 107 (5), 1894-1899. doi:10.1073/pnas.0914845107

Cohen, A. S., Geng, L., Zhao, P., Fu, A., Schulte, M. L., Graves-Deal, R., et al. (2020). Combined Blockade of EGFR and Glutamine Metabolism in Preclinical Models of Colorectal Cancer. Transl Oncol. 13 (10), 100828. doi:10.1016/ j.tranon.2020.100828

Coppedè, F., Lopomo, A., Spisni, R., and Migliore, L. (2014). Genetic and Epigenetic Biomarkers for Diagnosis, Prognosis and Treatment of Colorectal Cancer. World J. Gastroenterol. 20 (4), 943-956. doi:10.3748/wjg.v20.i4.943

Corcoran, R. B., Atreya, C. E., Falchook, G. S., Kwak, E. L., Ryan, D. P., Bendell, J. C., et al. (2015). Combined BRAF and MEK Inhibition with Dabrafenib and Trametinib in BRAF V600-Mutant Colorectal Cancer. J. Clin. Oncol. 33 (34), 4023-4031. doi:10.1200/JCO.2015.63.2471

Cordin, O., Banroques, J., Tanner, N. K., and Linder, P. (2006). The DEAD-Box Protein Family of RNA Helicases. Gene 367, 17-37. doi:10.1016/ j.gene.2005.10.019

Csibi, A., Fendt, S. M., Li, C., Poulogiannis, G., Choo, A. Y., Chapski, D. J., et al. (2013). The mTORC1 Pathway Stimulates Glutamine Metabolism and Cell Proliferation by Repressing SIRT4. Cell 153 (4), 840-854. doi:10.1016/ j.cell.2013.04.023

Cunningham, J. T., Moreno, M. V., Lodi, A., Ronen, S. M., and Ruggero, D. (2014). Protein and Nucleotide Biosynthesis Are Coupled by a Single Rate-Limiting Enzyme, PRPS2, to Drive Cancer. Cell 157 (5), 1088-1103. doi:10.1016/ j.cell.2014.03.052

D’Aguanno, S., Barcaroli, D., Rossi, C., Zucchelli, M., Ciavardelli, D., Cortese, C., et al. (2014). p63 Isoforms Regulate Metabolism of Cancer Stem Cells. J. Proteome Res. 13 (4), 2120-2136. doi:10.1021/pr4012574

Daemen, A., Liu, B., Song, K., Kwong, M., Gao, M., Hong, R., et al. (2018). PanCancer Metabolic Signature Predicts Co-dependency on Glutaminase and De Novo Glutathione Synthesis Linked to a High-Mesenchymal Cell State. Cell Metab 28 (3), 383-e9. doi:10.1016/j.cmet.2018.06.003

Dang, C. V., O’Donnell, K. A., Zeller, K. I., Nguyen, T., Osthus, R. C., and Li, F. (2006). The C-Myc Target Gene Network. Semin. Cancer Biol. 16 (4), 253-264. doi:10.1016/j.semcancer.2006.07.014

David, C. J., Chen, M., Assanah, M., Canoll, P., and Manley, J. L. (2010). HnRNP Proteins Controlled by C-Myc Deregulate Pyruvate Kinase mRNA Splicing in Cancer. Nature 463 (7279), 364-368. doi:10.1038/nature08697

De Pauw, I., Wouters, A., Van den Bossche, J., Peeters, M., Pauwels, P., Deschoolmeester, V., et al. (2016). Preclinical and Clinical Studies on Afatinib in Monotherapy and in Combination Regimens: Potential Impact in Colorectal Cancer. Pharmacol. Ther. 166, 71-83. doi:10.1016/ j.pharmthera.2016.06.014

Dekker, E., Tanis, P. J., Vleugels, J. L. A., Kasi, P. M., and Wallace, M. B. (2019). Colorectal Cancer. Lancet 394 (10207), 1467-1480. doi:10.1016/S01406736(19)32319-0

Devic, S. (2016). Warburg Effect - a Consequence or the Cause of Carcinogenesis? J. Cancer 7 (7), 817-822. doi:10.7150/jca.14274

Do, K., Speranza, G., Bishop, R., Khin, S., Rubinstein, L., Kinders, R. J., et al. (2015). Biomarker-driven Phase 2 Study of MK-2206 and Selumetinib (AZD6244, ARRY-142886) in Patients with Colorectal Cancer. Invest. New Drugs 33 (3), 720-728. doi:10.1007/s10637-015-0212-z

Dong, Y., Tu, R., Liu, H., and Qing, G. (2020). Regulation of Cancer Cell Metabolism: Oncogenic MYC in the Driver's Seat. Signal. Transduct Target. Ther. 5 (1), 124. doi:10.1038/s41392-020-00235-2

Du, L., Wang, H., He, L., Zhang, J., Ni, B., Wang, X., et al. (2008). CD44 Is of Functional Importance for Colorectal Cancer Stem Cells. Clin. Cancer Res. 14 (21), 6751-6760. doi:10.1158/1078-0432.CCR-08-1034

Duchartre, Y., Kim, Y. M., and Kahn, M. (2016). The Wnt Signaling Pathway in Cancer. Crit. Rev. Oncol. Hematol. 99, 141-149. doi:10.1016/ j.critrevonc.2015.12.005

Dunlop, M. G., Tenesa, A., Farrington, S. M., Ballereau, S., Brewster, D. H., Koessler, T., et al. (2013). Cumulative Impact of Common Genetic Variants and Other Risk Factors on Colorectal Cancer Risk in 42,103 Individuals. Gut 62 (6), 871-881. doi:10.1136/gutjnl-2011-300537

Ewing, I., Hurley, J. J., Josephides, E., and Millar, A. (2014). The Molecular Genetics of Colorectal Cancer. Frontline Gastroenterol. 5 (1), 26-30. doi:10.1136/ flgastro-2013-100329
Fang, Y., Shen, Z. Y., Zhan, Y. Z., Feng, X. C., Chen, K. L., Li, Y. S., et al. (2019). CD36 Inhibits $\beta$-catenin/c-myc-mediated Glycolysis through Ubiquitination of GPC4 to Repress Colorectal Tumorigenesis. Nat. Commun. 10 (1), 3981. doi:10.1038/s41467-019-11662-3

Fernandes, M. S., Sanches, J. M., and Seruca, R. (2018). "Targeting the PI3K Signalling as a Therapeutic Strategy in Colorectal Cancer," in Targeted Therapy of Colorectal Cancer Subtypes. Editor P. Jordan (Cham: Springer International Publishing), 35-53. doi:10.1007/978-3-030-02771-1_4

Fico, A., De Chevigny, A., Egea, J., Bösl, M. R., Cremer, H., Maina, F., et al. (2012). Modulating Glypican4 Suppresses Tumorigenicity of Embryonic Stem Cells while Preserving Self-Renewal and Pluripotency. Stem Cells 30 (9), 1863-1874. doi:10.1002/stem.1165

Frödin, M., Antal, T. L., Dümmler, B. A., Jensen, C. J., Deak, M., Gammeltoft, S., et al. (2002). A Phosphoserine/threonine-Binding Pocket in AGC Kinases and PDK1 Mediates Activation by Hydrophobic Motif Phosphorylation. EMBO J. 21 (20), 5396-5407. doi:10.1093/emboj/cdf551

Fu, K., Sun, X., Wier, E. M., Hodgson, A., Liu, Y., Sears, C. L., et al. (2016). Sam68/ KHDRBS1 Is Critical for colon Tumorigenesis by Regulating Genotoxic StressInduced NF-kB Activation. Elife 5, e15018. doi:10.7554/eLife.15018

Fukuda, R., Zhang, H., Kim, J. W., Shimoda, L., Dang, C. V., and Semenza, G. L. (2007). HIF-1 Regulates Cytochrome Oxidase Subunits to Optimize Efficiency of Respiration in Hypoxic Cells. Cell 129 (1), 111-122. doi:10.1016/ j.cell.2007.01.047

Gabay, M., Li, Y., and Felsher, D. W. (2014). MYC Activation Is a Hallmark of Cancer Initiation and Maintenance. Cold Spring Harb Perspect. Med. 4 (6), a014241. doi:10.1101/cshperspect.a014241

Gan, H. K., van den Bent, M., Lassman, A. B., Reardon, D. A., and Scott, A. M. (2017). Antibody-drug Conjugates in Glioblastoma Therapy: the Right Drugs to the Right Cells. Nat. Rev. Clin. Oncol. 14 (11), 695-707. doi:10.1038/ nrclinonc.2017.95

Gan, Y., Shi, C., Inge, L., Hibner, M., Balducci, J., and Huang, Y. (2010). Differential Roles of ERK and Akt Pathways in Regulation of EGFR-Mediated Signaling and Motility in Prostate Cancer Cells. Oncogene 29 (35), 4947-4958. doi:10.1038/ onc.2010.240

Gao, P., Tchernyshyov, I., Chang, T. C., Lee, Y. S., Kita, K., Ochi, T., et al. (2009). c-Myc Suppression of miR-23a/b Enhances Mitochondrial Glutaminase Expression and Glutamine Metabolism. Nature 458 (7239), 762-765. doi:10.1038/nature07823

Gao, X., Wang, H., Yang, J. J., Liu, X., and Liu, Z. R. (2012). Pyruvate Kinase M2 Regulates Gene Transcription by Acting as a Protein Kinase. Mol. Cell 45 (5), 598-609. doi:10.1016/j.molcel.2012.01.001

García-Foncillas, J., Sunakawa, Y., Aderka, D., Wainberg, Z., Ronga, P., Witzler, P., et al. (2019). Distinguishing Features of Cetuximab and Panitumumab in Colorectal Cancer and Other Solid Tumors. Front. Oncol. 9, 849. doi:10.3389/fonc.2019.00849

Garcia-Ortega, M. B., Lopez, G. J., Jimenez, G., Garcia-Garcia, J. A., Conde, V., Boulaiz, H., et al. (2017). Clinical and Therapeutic Potential of Protein Kinase PKR in Cancer and Metabolism. Expert Rev. Mol. Med. 19, e9. doi:10.1017/ erm.2017.11

Gaumann, A. K., Kiefer, F., Alfer, J., Lang, S. A., Geissler, E. K., and Breier, G. (2016). Receptor Tyrosine Kinase Inhibitors: Are They Real Tumor Killers? Int. J. Cancer 138 (3), 540-554. doi:10.1002/ijc.29499

Giacobbe, A., Bongiorno-Borbone, L., Bernassola, F., Terrinoni, A., Markert, E. K., Levine, A. J., et al. (2013). p63 Regulates Glutaminase 2 Expression. Cell Cycle 12 (9), 1395-1405. doi:10.4161/cc.24478

Godet, A. C., David, F., Hantelys, F., Tatin, F., Lacazette, E., Garmy-Susini, B., et al. (2019). IRES Trans-acting Factors, Key Actors of the Stress Response. Int. J. Mol. Sci. 20 (4), 924. doi:10.3390/ijms20040924

Gutteridge, R. E., Singh, C. K., Ndiaye, M. A., and Ahmad, N. (2017). Targeted Knockdown of polo-like Kinase 1 Alters Metabolic Regulation in Melanoma. Cancer Lett. 394, 13-21. doi:10.1016/j.canlet.2017.02.013

Hagman, H., Frödin, J. E., Berglund, Å., Sundberg, J., Vestermark, L. W., Albertsson, M., et al. (2016). A Randomized Study of KRAS-Guided Maintenance Therapy with Bevacizumab, Erlotinib or Metronomic Capecitabine after First-Line Induction Treatment of Metastatic Colorectal Cancer: the Nordic ACT2 Trial. Ann. Oncol. 27 (1), 140-147. doi:10.1093/ annonc/mdv490 
Hamabe, A., Yamamoto, H., Konno, M., Uemura, M., Nishimura, J., Hata, T., et al. (2014). Combined Evaluation of Hexokinase 2 and Phosphorylated Pyruvate Dehydrogenase-E1 $\alpha$ in Invasive Front Lesions of Colorectal Tumors Predicts Cancer Metabolism and Patient Prognosis. Cancer Sci. 105 (9), 1100-1108. doi:10.1111/cas.12487

Hao, Y., Samuels, Y., Li, Q., Krokowski, D., Guan, B. J., Wang, C., et al. (2016). Oncogenic PIK3CA Mutations Reprogram Glutamine Metabolism in Colorectal Cancer. Nat. Commun. 7 (1), 11971. doi:10.1038/ncomms11971

Hao, Y., Zhao, S., and Wang, Z. (2014). Targeting the Protein-Protein Interaction between IRS1 and Mutant P110a for Cancer Therapy. Toxicol. Pathol. 42 (1), 140-147. doi:10.1177/0192623313506794

Hashimoto, K., Nakagawa, Y., Morikawa, H., Niki, M., Egashira, Y., Hirata, I., et al. (2001). Co-overexpression of DEAD Box Protein Rck/p54 and C-Myc Protein in Human Colorectal Adenomas and the Relevance of Their Expression in Cultured Cell Lines. Carcinogenesis 22 (12), 1965-1970. doi:10.1093/carcin/ 22.12.1965

Hayashi, K., Mitani, S., Taniguchi, H., Hamauchi, S., Sugiyama, K., Tsushima, T., et al. (2017). Efficacy of Panitumumab Plus Irinotecan versus Cetuximab Plus Irinotecan in Patients with Wild-type KRAS Exon2 Metastatic Colorectal Cancer Previously Treated with Bevacizumab within 6 Months. Jco 35 (4_Suppl. 1), 800. doi:10.1200/JCO.2017.35.4_suppl.800

He, X., Arslan, A. D., Ho, T. T., Yuan, C., Stampfer, M. R., and Beck, W. T. (2014). Involvement of Polypyrimidine Tract-Binding Protein (PTBP1) in Maintaining Breast Cancer Cell Growth and Malignant Properties. Oncogenesis 3 (1), e84. doi:10.1038/oncsis.2013.47

Ho, N., and Coomber, B. L. (2016). Hexokinase II Expression Is Correlated with Colorectal Cancer Prognosis. Cancer Treat. Commun. 6, 11-16. doi:10.1016/ j.ctrc.2016.02.008

Hocking, C. M., and Price, T. J. (2014). Panitumumab in the Management of Patients with KRAS Wild-type Metastatic Colorectal Cancer. Therap Adv. Gastroenterol. 7 (1), 20-37. doi:10.1177/1756283X13498660

Hofmanová, J., Slavík, J., Ciganek, M., Ovesná, P., Tylichová, Z., Karasová, M., et al. (2021). Complex Alterations of Fatty Acid Metabolism and Phospholipidome Uncovered in Isolated Colon Cancer Epithelial Cells. Int. J. Mol. Sci. 22 (13), 6650. doi:10.3390/ijms22136650

Holczer, M., Besze, B., Zámbó, V., Csala, M., Bánhegyi, G., and Kapuy, O. (20182018). Epigallocatechin-3-gallate (EGCG) Promotes Autophagydependent Survival via Influencing the Balance of mTOR-AMPK Pathways upon Endoplasmic Reticulum Stress. Oxidative Med. Cell. longevity 2018, 1-15. doi:10.1155/2018/6721530

Hong, S. N., Kim, S. J., Kim, E. R., Chang, D. K., and Kim, Y. H. (2016). Epigenetic Silencing of NDRG2 Promotes Colorectal Cancer Proliferation and Invasion. J. Gastroenterol. Hepatol. 31 (1), 164-171. doi:10.1111/jgh.13068

Horinaka, M., Yoshida, T., Shiraishi, T., Nakata, S., Wakada, M., Nakanishi, R., et al. (2005). Luteolin Induces Apoptosis via Death Receptor 5 Upregulation in Human Malignant Tumor Cells. Oncogene 24 (48), 7180-7189. doi:10.1038/ sj.onc. 1208874

Hosono, K., Endo, H., Takahashi, H., Sugiyama, M., Uchiyama, T., Suzuki, K., et al. (2010). Metformin Suppresses Azoxymethane-Induced Colorectal Aberrant Crypt Foci by Activating AMP-Activated Protein Kinase. Mol. Carcinog 49 (7), 662-671. doi:10.1002/mc.20637

Houten, S. M., Violante, S., Ventura, F. V., and Wanders, R. J. (2016). The Biochemistry and Physiology of Mitochondrial Fatty Acid $\beta$-Oxidation and its Genetic Disorders. Annu. Rev. Physiol. 78 (1), 23-44. doi:10.1146/annurevphysiol-021115-105045

Hoxhaj, G., and Manning, B. D. (2020). The PI3K-AKT Network at the Interface of Oncogenic Signalling and Cancer Metabolism. Nat. Rev. Cancer 20 (2), 74-88. doi:10.1038/s41568-019-0216-7

Huang, Y. T., Lin, Y. W., Chiu, H. M., and Chiang, B. H. (2016). Curcumin Induces Apoptosis of Colorectal Cancer Stem Cells by Coupling with CD44 Marker. J. Agric. Food Chem. 64 (11), 2247-2253. doi:10.1021/acs.jafc.5b05649

Hutton, J. E., Wang, X., Zimmerman, L. J., Slebos, R. J., Trenary, I. A., Young, J. D., et al. (2016). Oncogenic KRAS and BRAF Drive Metabolic Reprogramming in Colorectal Cancer. Mol. Cell Proteomics 15 (9), 2924-2938. doi:10.1074/ mcp.M116.058925

Hwang, K., Yoon, J. H., Lee, J. H., and Lee, S. (2021). Recent Advances in Monoclonal Antibody Therapy for Colorectal Cancers. Biomedicines 9 (1), 39. doi:10.3390/biomedicines 9010039
Irwin, D. M., and Tan, H. (2008). Molecular Evolution of the Vertebrate Hexokinase Gene Family: Identification of a Conserved Fifth Vertebrate Hexokinase Gene. Comp. Biochem. Physiol. Part. D Genomics Proteomics 3 (1), 96-107. doi:10.1016/j.cbd.2007.11.002

Israelsen, W. J., Dayton, T. L., Davidson, S. M., Fiske, B. P., Hosios, A. M., Bellinger, G., et al. (2013). PKM2 Isoform-specific Deletion Reveals a Differential Requirement for Pyruvate Kinase in Tumor Cells. Cell 155 (2), 397-409. doi:10.1016/j.cell.2013.09.025

Israelsen, W. J., and Vander Heiden, M. G. (2015). Pyruvate Kinase: Function, Regulation and Role in Cancer. Semin. Cell Dev Biol 43, 43-51. doi:10.1016/ j.semcdb.2015.08.004

Iwamoto, M., Kawada, K., Nakamoto, Y., Itatani, Y., Inamoto, S., Toda, K., et al. (2014). Regulation of 18F-FDG Accumulation in Colorectal Cancer Cells with Mutated KRAS. J. Nucl. Med. 55 (12), 2038-2044. doi:10.2967/ jnumed.114.142927

James, A. D., Richardson, D. A., Oh, I. W., Sritangos, P., Attard, T., Barrett, L., et al. (2020). Cutting off the Fuel Supply to Calcium Pumps in Pancreatic Cancer Cells: Role of Pyruvate Kinase-M2 (PKM2). Br. J. Cancer 122 (2), 266-278. doi:10.1038/s41416-019-0675-3

Jiang, C. H., Sun, T. L., Xiang, D. X., Wei, S. S., and Li, W. Q. (2018). Anticancer Activity and Mechanism of Xanthohumol: A Prenylated Flavonoid from Hops (Humulus Lupulus L). Front. Pharmacol. 9, 530. doi:10.3389/fphar.2018.00530

Jiang, W., and Ji, M. (2019). Receptor Tyrosine Kinases in PI3K Signaling: The Therapeutic Targets in Cancer. Semin. Cancer Biol. 59, 3-22. doi:10.1016/ j.semcancer.2019.03.006

Jin, L., Alesi, G. N., and Kang, S. (2016). Glutaminolysis as a Target for Cancer Therapy. Oncogene 35 (28), 3619-3625. doi:10.1038/onc.2015.447

Johnson, C. M., Wei, C., Ensor, J. E., Smolenski, D. J., Amos, C. I., Levin, B., et al. (2013). Meta-analyses of Colorectal Cancer Risk Factors. Cancer Causes Control 24 (6), 1207-1222. doi:10.1007/s10552-013-0201-5

Jonker, D. J., Nott, L., Yoshino, T., Gill, S., Shapiro, J., Ohtsu, A., et al. (2018). Napabucasin versus Placebo in Refractory Advanced Colorectal Cancer: a Randomised Phase 3 Trial. Lancet Gastroenterol. Hepatol. 3 (4), 263-270. doi:10.1016/S2468-1253(18)30009-8

Kang, F., Wang, Y., Luo, Y., and Zhang, Y. (2020). NDRG2 Gene Expression Pattern in Ovarian Cancer and its Specific Roles in Inhibiting Cancer Cell Proliferation and Suppressing Cancer Cell Apoptosis. J. Ovarian Res. 13 (1), 48. doi:10.1186/s13048-020-00649-0

Kawada, K., Nakamoto, Y., Kawada, M., Hida, K., Matsumoto, T., Murakami, T., et al. (2012). Relationship between 18F-Fluorodeoxyglucose Accumulation and KRAS/BRAF Mutations in Colorectal Cancer. Clin. Cancer Res. 18 (6), 1696-1703. doi:10.1158/1078-0432.CCR-11-1909

Kemper, K., Prasetyanti, P. R., De Lau, W., Rodermond, H., Clevers, H., and Medema, J. P. (2012). Monoclonal Antibodies against Lgr5 Identify Human Colorectal Cancer Stem Cells. Stem Cells 30 (11), 2378-2386. doi:10.1002/ stem.1233

Kerk, S. A., Papagiannakopoulos, T., Shah, Y. M., and Lyssiotis, C. A. (2021). Metabolic Networks in Mutant KRAS-Driven Tumours: Tissue Specificities and the Microenvironment. Nat. Rev. Cancer 21 (8), 510-525. doi:10.1038/s41568021-00375-9

Keum, N., and Giovannucci, E. (2019). Global burden of Colorectal Cancer: Emerging Trends, Risk Factors and Prevention Strategies. Nat. Rev. Gastroenterol. Hepatol. 16 (12), 713-732. doi:10.1038/s41575-019-0189-8

Kim, B. H., Yi, E. H., and Ye, S. K. (2016). Signal Transducer and Activator of Transcription 3 as a Therapeutic Target for Cancer and the Tumor Microenvironment. Arch. Pharm. Res. 39 (8), 1085-1099. doi:10.1007/ s12272-016-0795-8

Kim, Y., Lee, Y. S., Kang, S. W., Kim, S., Kim, T. Y., Lee, S. H., et al. (2019). Loss of PKM2 in Lgr5+ Intestinal Stem Cells Promotes Colitis-Associated Colorectal Cancer. Sci. Rep. 9 (1), 6212. doi:10.1038/s41598-019-42707-8

Kloten, V., Schlensog, M., Eschenbruch, J., Gasthaus, J., Tiedemann, J., Mijnes, J., et al. (2016). Abundant NDRG2 Expression Is Associated with Aggressiveness and Unfavorable Patients' Outcome in Basal-like Breast Cancer. PLoS One 11 (7), e0159073. doi:10.1371/journal.pone.0159073

Klute, K., Garrett-Mayer, E., Halabi, S., Mangat, P. K., Nazemzadeh, R., Yost, K. J., et al. (2020). Cobimetinib Plus Vemurafenib $(\mathrm{C}+\mathrm{V})$ in Patients (Pts) with Colorectal Cancer (CRC) with BRAF V600E Mutations: Results from the TAPUR Study. Jco 38 (4_Suppl. 1), 122. doi:10.1200/JCO.2020.38.4_suppl.122 
Koh, M. Y., Lemos, R., Jr., Liu, X., and Powis, G. (2011). The Hypoxia-Associated Factor Switches Cells from HIF-1 $\alpha$ - to HIF-2 $\alpha$-dependent Signaling Promoting Stem Cell Characteristics, Aggressive Tumor Growth and Invasion. Cancer Res. 71 (11), 4015-4027. doi:10.1158/0008-5472.CAN-10-4142

Kolappan, S., Shen, D. L., Mosi, R., Sun, J., McEachern, E. J., Vocadlo, D. J., et al. (2015). Structures of Lactate Dehydrogenase A (LDHA) in Apo, Ternary and Inhibitor-Bound Forms. Acta Crystallogr. D Biol. Crystallogr. 71 (Pt 2), 185-195. doi:10.1107/S1399004714024791

Kopetz, S., Grothey, A., Yaeger, R., Van Cutsem, E., Desai, J., Yoshino, T., et al. (2019). Encorafenib, Binimetinib, and Cetuximab in BRAF V600E-Mutated Colorectal Cancer. N. Engl. J. Med. 381 (17), 1632-1643. doi:10.1056/ NEJMoa1908075

Krasnov, G. S., Dmitriev, A. A., Sadritdinova, A. F., Fedorova, M. S., Snezhkina, A. V., Melnikova, N. V., et al. (2016). Evaluation of Hexokinase Gene Expression in Colorectal Cancer Using Bioinformatics Tools. Biophysics 60 (6), 870-875. doi:10.1134/s0006350915060172

Kudryavtseva, A. V., Lipatova, A. V., Zaretsky, A. R., Moskalev, A. A., Fedorova, M. S., Rasskazova, A. S., et al. (2016). Important Molecular Genetic Markers of Colorectal Cancer. Oncotarget 7 (33), 53959-53983. doi:10.18632/ oncotarget.9796

Ladanyi, A., Mukherjee, A., Kenny, H. A., Johnson, A., Mitra, A. K., Sundaresan, S., et al. (2018). Adipocyte-induced CD36 Expression Drives Ovarian Cancer Progression and Metastasis. Oncogene 37 (17), 2285-2301. doi:10.1038/s41388017-0093-z

Lau, A. N., Israelsen, W. J., Roper, J., Sinnamon, M. J., Georgeon, L., Dayton, T. L., et al. (2017). PKM2 Is Not Required for colon Cancer Initiated by APC Loss. Cancer Metab. 5 (1), 10. doi:10.1186/s40170-017-0172-1

Lee, H. J., Li, C. F., Ruan, D., He, J., Montal, E. D., Lorenz, S., et al. (2019). Nonproteolytic Ubiquitination of Hexokinase 2 by HectH9 Controls Tumor Metabolism and Cancer Stem Cell Expansion. Nat. Commun. 10 (1), 2625. doi:10.1038/s41467-019-10374-y

Lemberg, K. M., Vornov, J. J., Rais, R., and Slusher, B. S. (2018). We're Not "DON" yet: Optimal Dosing and Prodrug Delivery of 6-Diazo-5-Oxo-LNorleucine. Mol. Cancer Ther. 17 (9), 1824-1832. doi:10.1158/15357163.MCT-17-1148

Lemmon, M. A., and Schlessinger, J. (2010). Cell Signaling by Receptor Tyrosine Kinases. Cell 141 (7), 1117-1134. doi:10.1016/j.cell.2010.06.011

Li, H., and Jogl, G. (2009). Structural and Biochemical Studies of TIGAR (TP53Induced Glycolysis and Apoptosis Regulator). J. Biol. Chem. 284 (3), 1748-1754. doi:10.1074/jbc.M807821200

Li, L., Peng, G., Liu, X., Zhang, Y., Han, H., and Liu, Z. R. (2020a). Pyruvate Kinase M2 Coordinates Metabolism Switch between Glycolysis and Glutaminolysis in Cancer Cells. iScience 23 (11), 101684. doi:10.1016/j.isci.2020.101684

Li, R., Yu, C., Jiang, F., Gao, L., Li, J., Wang, Y., et al. (2013). Overexpression of N-Myc Downstream-Regulated Gene 2 (NDRG2) Regulates the Proliferation and Invasion of Bladder Cancer Cells In Vitro and In Vivo. PLoS One 8 (10), e76689. doi:10.1371/journal.pone. 0076689

Li, S., Cheng, B., Hou, L., Huang, L., Cui, Y., Xu, D., et al. (2018). Dioscin Inhibits colon Cancer Cells' Growth by Reactive Oxygen Species-Mediated Mitochondrial Dysfunction and P38 and JNK Pathways. Anticancer Drugs 29 (3), 234-242. doi:10.1097/CAD.0000000000000590

Li, T., Mao, C., Wang, X., Shi, Y., and Tao, Y. (2020b). Epigenetic Crosstalk between Hypoxia and Tumor Driven by HIF Regulation. J. Exp. Clin. Cancer Res. 39 (1), 224. doi:10.1186/s13046-020-01733-5

Li, Y., Wang, Y., Liu, Z., Guo, X., Miao, Z., and Ma, S. (2020c). Atractylenolide I Induces Apoptosis and Suppresses Glycolysis by Blocking the JAK2/STAT3 Signaling Pathway in Colorectal Cancer Cells. Front. Pharmacol. 11 (273), 273. doi:10.3389/fphar.2020.00273

Li, Z. (2013). CD133: a Stem Cell Biomarker and beyond. Exp. Hematol. Oncol. 2 (1), 17. doi:10.1186/2162-3619-2-17

Liao, W. T., Liu, J. L., Wang, Z. G., Cui, Y. M., Shi, L., Li, T. T., et al. (2013). High Expression Level and Nuclear Localization of Sam68 Are Associated with Progression and Poor Prognosis in Colorectal Cancer. BMC Gastroenterol. 13, 126. doi:10.1186/1471-230X-13-126

Lin, L., Ding, Y., Wang, Y., Wang, Z., Yin, X., Yan, G., et al. (2017). Functional Lipidomics: Palmitic Acid Impairs Hepatocellular Carcinoma Development by Modulating Membrane Fluidity and Glucose Metabolism. Hepatology 66 (2), 432-448. doi:10.1002/hep.29033
Liu, C., Kelnar, K., Liu, B., Chen, X., Calhoun-Davis, T., Li, H., et al. (2011). The microRNA miR-34a Inhibits Prostate Cancer Stem Cells and Metastasis by Directly Repressing CD44. Nat. Med. 17 (2), 211-215. doi:10.1038/nm.2284

Liu, W., Li, W., Liu, H., and Yu, X. (2019). Xanthohumol Inhibits Colorectal Cancer Cells via Downregulation of Hexokinases II-Mediated Glycolysis. Int. J. Biol. Sci. 15 (11), 2497-2508. doi:10.7150/ijbs.37481

Liu, Y. H., Wei, X. L., Hu, G. Q., and Wang, T. X. (2015). Quinolone-indolone Conjugate Induces Apoptosis by Inhibiting the EGFR-STAT3-HK2 Pathway in Human Cancer Cells. Mol. Med. Rep. 12 (2), 2749-2756. doi:10.3892/ mmr.2015.3716

Louderbough, J. M., and Schroeder, J. A. (2011). Understanding the Dual Nature of CD44 in Breast Cancer Progression. Mol. Cancer Res. 9 (12), 1573-1586. doi:10.1158/1541-7786.MCR-11-0156

$\mathrm{Lu}, \mathrm{Z}$., and Hunter, T. (2018). Metabolic Kinases Moonlighting as Protein Kinases. Trends Biochem. Sci. 43 (4), 301-310. doi:10.1016/j.tibs.2018.01.006

Lu, Z. (2012). Nonmetabolic Functions of Pyruvate Kinase Isoform M2 in Controlling Cell Cycle Progression and Tumorigenesis. Chin. J. Cancer 31 (1), 5-7. doi:10.5732/cjc.011.10446

Luo, W., Hu, H., Chang, R., Zhong, J., Knabel, M., O’Meally, R., et al. (2011). Pyruvate Kinase M2 Is a PHD3-Stimulated Coactivator for Hypoxia-Inducible Factor 1. Cell 145 (5), 732-744. doi:10.1016/j.cell.2011.03.054

Luo, Y., Shang, P., and Li, D. (2017). Luteolin: A Flavonoid that Has Multiple Cardio-Protective Effects and its Molecular Mechanisms. Front. Pharmacol. 8 (692), 692. doi:10.3389/fphar.2017.00692

MacDonald, B. T., Tamai, K., and He, X. (2009). Wnt/beta-catenin Signaling: Components, Mechanisms, and Diseases. Dev. Cell 17 (1), 9-26. doi:10.1016/ j.devcel.2009.06.016

Makinoshima, H., Takita, M., Matsumoto, S., Yagishita, A., Owada, S., Esumi, H., et al. (2014). Epidermal Growth Factor Receptor (EGFR) Signaling Regulates Global Metabolic Pathways in EGFR-Mutated Lung Adenocarcinoma. J. Biol. Chem. 289 (30), 20813-20823. doi:10.1074/jbc.M114.575464

Mao, Z., Han, X., Chen, D., Xu, Y., Xu, L., Yin, L., et al. (2019). Potent Effects of Dioscin against Hepatocellular Carcinoma through Regulating TP53-Induced Glycolysis and Apoptosis Regulator (TIGAR)-mediated Apoptosis, Autophagy, and DNA Damage. Br. J. Pharmacol. 176 (7), 919-937. doi:10.1111/bph.14594

Meric-Bernstam, F., Hurwitz, H., Raghav, K. P. S., McWilliams, R. R., Fakih, M., VanderWalde, A., et al. (2019). Pertuzumab Plus Trastuzumab for HER2Amplified Metastatic Colorectal Cancer (MyPathway): an Updated Report from a Multicentre, Open-Label, Phase 2a, Multiple Basket Study. Lancet Oncol. 20 (4), 518-530. doi:10.1016/S1470-2045(18)30904-5

Merlos-Suárez, A., Barriga, F. M., Jung, P., Iglesias, M., Céspedes, M. V., Rossell, D., et al. (2011). The Intestinal Stem Cell Signature Identifies Colorectal Cancer Stem Cells and Predicts Disease Relapse. Cell Stem Cell 8 (5), 511-524. doi:10.1016/j.stem.2011.02.020

Misale, S., Yaeger, R., Hobor, S., Scala, E., Janakiraman, M., Liska, D., et al. (2012). Emergence of KRAS Mutations and Acquired Resistance to Anti-EGFR Therapy in Colorectal Cancer. Nature 486 (7404), 532-536. doi:10.1038/ nature11156

Morath, I., Hartmann, T. N., and Orian-Rousseau, V. (2016). CD44: More Than a Mere Stem Cell Marker. Int. J. Biochem. Cell Biol 81 (Pt A), 166-173. doi:10.1016/j.biocel.2016.09.009

Morishita, K., Nakahata, S., and Ichikawa, T. (2021). Pathophysiological Significance of N-Myc Downstream-Regulated Gene 2 in Cancer Development through Protein Phosphatase 2A Phosphorylation Regulation. Cancer Sci. 112 (1), 22-30. doi:10.1111/cas.14716

Munro, M. J., Wickremesekera, S. K., Peng, L., Tan, S. T., and Itinteang, T. (2018). Cancer Stem Cells in Colorectal Cancer: a Review. J. Clin. Pathol. 71 (2), 110-116. doi:10.1136/jclinpath-2017-204739

Murata, S., Yanagisawa, K., Fukunaga, K., Oda, T., Kobayashi, A., Sasaki, R., et al. (2010). Fatty Acid Synthase Inhibitor Cerulenin Suppresses Liver Metastasis of colon Cancer in Mice. Cancer Sci. 101 (8), 1861-1865. doi:10.1111/j.13497006.2010.01596.x

Nath, A., Li, I., Roberts, L. R., and Chan, C. (2015). Elevated Free Fatty Acid Uptake via CD36 Promotes Epithelial-Mesenchymal Transition in Hepatocellular Carcinoma. Sci. Rep. 5 (1), 14752. doi:10.1038/srep14752

Ng, K., Tabernero, J., Hwang, J., Bajetta, E., Sharma, S., Del Prete, S. A., et al. (2013). Phase II Study of Everolimus in Patients with Metastatic Colorectal Adenocarcinoma Previously Treated with Bevacizumab-, Fluoropyrimidine-, 
Oxaliplatin-, and Irinotecan-Based Regimens. Clin. Cancer Res. 19 (14), 3987-3995. doi:10.1158/1078-0432.CCR-13-0027

Nguyen, H. T., and Duong, H. Q. (2018). The Molecular Characteristics of Colorectal Cancer: Implications for Diagnosis and Therapy. Oncol. Lett. 16 (1), 9-18. doi:10.3892/ol.2018.8679

Nishimura, Y., Takiguchi, S., Ito, S., and Itoh, K. (2015). EGF-stimulated AKT A-ctivation I-s M-ediated by EGFR R-ecycling via an E-arly E-ndocytic $\mathrm{P}$-athway in a $\mathrm{G}$-efitinib-resistant $\mathrm{H}$-uman L-ung $\mathrm{C}$-ancer $\mathrm{C}$-ell L-ine. Int. J. Oncol. 46 (4), 1721-1729. doi:10.3892/ijo.2015.2871

Nitulescu, G. M., Van De Venter, M., Nitulescu, G., Ungurianu, A., Juzenas, P., Peng, Q., et al. (2018). The Akt Pathway in Oncology Therapy and beyond (Review). Int. J. Oncol. 53 (6), 2319-2331. doi:10.3892/ijo.2018.4597

Noorolyai, S., Shajari, N., Baghbani, E., Sadreddini, S., and Baradaran, B. (2019). The Relation between PI3K/AKT Signalling Pathway and Cancer. Gene 698, 120-128. doi:10.1016/j.gene.2019.02.076

O'Sullivan, K. E., Breen, E. P., Gallagher, H. C., Buggy, D. J., and Hurley, J. P. (2016). Understanding STAT3 Signaling in Cardiac Ischemia. Basic Res. Cardiol. 111 (3), 27. doi:10.1007/s00395-016-0543-8

Onyoh, E. F., Hsu, W. F., Chang, L. C., Lee, Y. C., Wu, M. S., and Chiu, H. M. (2019). The Rise of Colorectal Cancer in Asia: Epidemiology, Screening, and Management. Curr. Gastroenterol. Rep. 21 (8), 36. doi:10.1007/s11894-0190703-8

Orian-Rousseau, V. (2015). CD44 Acts as a Signaling Platform Controlling Tumor Progression and Metastasis. Front. Immunol. 6 (154), 154. doi:10.3389/ fimmu.2015.00154

Ou, B., Sun, H., Zhao, J., Xu, Z., Liu, Y., Feng, H., et al. (2019). Polo-like Kinase 3 Inhibits Glucose Metabolism in Colorectal Cancer by Targeting HSP90/ STAT3/HK2 Signaling. J. Exp. Clin. Cancer Res. 38 (1), 426. doi:10.1186/ s13046-019-1418-2

Ou, B., Zhao, J., Guan, S., Wangpu, X., Zhu, C., Zong, Y., et al. (2016). Plk2 Promotes Tumor Growth and Inhibits Apoptosis by Targeting Fbxw7/Cyclin E in Colorectal Cancer. Cancer Lett. 380 (2), 457-466. doi:10.1016/ j.canlet.2016.07.004

Pan, J., Fan, Z., Wang, Z., Dai, Q., Xiang, Z., Yuan, F., et al. (2019). CD36 Mediates Palmitate Acid-Induced Metastasis of Gastric Cancer via AKT/GSK-3 $\beta /$ $\beta$-catenin Pathway. J. Exp. Clin. Cancer Res. 38 (1), 52. doi:10.1186/s13046019-1049-7

Pan, T., Gao, L., Wu, G., Shen, G., Xie, S., Wen, H., et al. (2015). Elevated Expression of Glutaminase Confers Glucose Utilization via Glutaminolysis in Prostate Cancer. Biochem. Biophys. Res. Commun. 456 (1), 452-458. doi:10.1016/j.bbrc.2014.11.105

Pandurangan, A. K., and Esa, N. M. (2014). Luteolin, a Bioflavonoid Inhibits Colorectal Cancer through Modulation of Multiple Signaling Pathways: a Review. Asian Pac. J. Cancer Prev. 15 (14), 5501-5508. doi:10.7314/ apjcp.2014.15.14.5501

Papadopoulos, N., and Lennartsson, J. (2018). The PDGF/PDGFR Pathway as a Drug Target. Mol. Aspects Med. 62, 75-88. doi:10.1016/j.mam.2017.11.007

Parganas, E., Wang, D., Stravopodis, D., Topham, D. J., Marine, J. C., Teglund, S., et al. (1998). Jak2 Is Essential for Signaling through a Variety of Cytokine Receptors. Cell 93 (3), 385-395. doi:10.1016/s0092-8674(00)81167-8

Park, G. B., Chung, Y. H., and Kim, D. (2017). 2-Deoxy-D-glucose Suppresses the Migration and Reverses the Drug Resistance of colon Cancer Cells through ADAM Expression Regulation. Anticancer Drugs 28 (4), 410-420. doi:10.1097/ CAD. 0000000000000472

Pate, K. T., Stringari, C., Sprowl-Tanio, S., Wang, K., TeSlaa, T., Hoverter, N. P., et al. (2014). Wnt Signaling Directs a Metabolic Program of Glycolysis and Angiogenesis in colon Cancer. EMBO J. 33 (13), 1454-1473. doi:10.15252/ embj.201488598

Pignon, J. C., Grisanzio, C., Geng, Y., Song, J., Shivdasani, R. A., and Signoretti, S. (2013). p63-expressing Cells Are the Stem Cells of Developing Prostate, Bladder, and Colorectal Epithelia. Proc. Natl. Acad. Sci. U S A. 110 (20), 8105-8110. doi:10.1073/pnas.1221216110

Powell, S. M., Zilz, N., Beazer-Barclay, Y., Bryan, T. M., Hamilton, S. R., Thibodeau, S. N., et al. (1992). APC Mutations Occur Early during Colorectal Tumorigenesis. Nature 359 (6392), 235-237. doi:10.1038/359235a 0

Prakasam, G., and Bamezai, R. N. K. (2018). "Pyruvate Kinase," in Reference Module in Biomedical Sciences. Editors P. Boffetta and P. Hainaut (Oxford: Academic Press), 311-320. doi:10.1016/b978-0-12-801238-3.64999-1
Prigione, A., Rohwer, N., Hoffmann, S., Mlody, B., Drews, K., Bukowiecki, R., et al. (2014). HIF1a Modulates Cell Fate Reprogramming through Early Glycolytic Shift and Upregulation of PDK1-3 and PKM2. Stem cells 32 (2), 364-376. doi:10.1002/stem.1552

Qing, G., Li, B., Vu, A., Skuli, N., Walton, Z. E., Liu, X., et al. (2012). ATF4 Regulates MYC-Mediated Neuroblastoma Cell Death upon Glutamine deprivationATF4 Regulates MYC-Mediated Neuroblastoma Cell Death upon Glutamine Deprivation. Cancer cell 22 (5), 631-644. doi:10.1016/ j.ccr.2012.09.021

Qu, D., Shen, L., Liu, S., Li, H., Ma, Y., Zhang, R., et al. (2017). Chronic Inflammation Confers to the Metabolic Reprogramming Associated with Tumorigenesis of Colorectal Cancer. Cancer Biol. Ther. 18 (4), 237-244. doi:10.1080/15384047.2017.1294292

Rahl, P. B., and Young, R. A. (2014). MYC and Transcription Elongation. Cold Spring Harb Perspect. Med. 4 (1), a020990. doi:10.1101/ cshperspect.a020990

Rawla, P., Sunkara, T., and Barsouk, A. (2019). Epidemiology of Colorectal Cancer: Incidence, Mortality, Survival, and Risk Factors. Prz Gastroenterol. 14 (2), 89-103. doi:10.5114/pg.2018.81072

Ren, L., Ruiz-Rodado, V., Dowdy, T., Huang, S., Issaq, S. H., Beck, J., et al. (2020). Glutaminase-1 (GLS1) Inhibition Limits Metastatic Progression in Osteosarcoma. Cancer Metab. 8 (1), 4. doi:10.1186/s40170-020-0209-8

Requena, D. O., and Garcia-Buitrago, M. (2020). Molecular Insights into Colorectal Carcinoma. Arch. Med. Res. 51 (8), 839-844. doi:10.1016/j.arcmed.2020.09.014

Rosen, L. S., Jacobs, I. A., and Burkes, R. L. (2017). Bevacizumab in Colorectal Cancer: Current Role in Treatment and the Potential of Biosimilars. Target. Oncol. 12 (5), 599-610. doi:10.1007/s11523-017-0518-1

Sakane, H., Yamamoto, H., Matsumoto, S., Sato, A., and Kikuchi, A. (2012). Localization of Glypican-4 in Different Membrane Microdomains Is Involved in the Regulation of Wnt Signaling. J. Cell Sci 125 (Pt 2), 449-460. doi:10.1242/ jcs.091876

Salgado-García, R., Coronel-Hernández, J., Delgado-Waldo, I., Cantú de León, D., García-Castillo, V., López-Urrutia, E., et al. (2021). Negative Regulation of ULK1 by microRNA-106a in Autophagy Induced by a Triple Drug Combination in Colorectal Cancer Cells In Vitro. Genes (Basel) 12 (2), 245. doi:10.3390/genes 12020245

Samadder, N. J., Jasperson, K., and Burt, R. W. (2015). Hereditary and Common Familial Colorectal Cancer: Evidence for Colorectal Screening. Dig. Dis. Sci. 60 (3), 734-747. doi:10.1007/s10620-014-3465-z

Sato-Tadano, A., Suzuki, T., Amari, M., Takagi, K., Miki, Y., Tamaki, K., et al. (2013). Hexokinase II in Breast Carcinoma: a Potent Prognostic Factor Associated with Hypoxia-Inducible Factor-1 $\alpha$ and Ki-67. Cancer Sci. 104 (10), 1380-1388. doi:10.1111/cas.12238

Satoh, K., Yachida, S., Sugimoto, M., Oshima, M., Nakagawa, T., Akamoto, S., et al. (2017). Global Metabolic Reprogramming of Colorectal Cancer Occurs at Adenoma Stage and Is Induced by MYC. Proc. Natl. Acad. Sci. U S A. 114 (37), E7697-E7706. doi:10.1073/pnas.1710366114

Schcolnik-Cabrera, A., Chavez-Blanco, A., Dominguez-Gomez, G., Juarez, M., Lai, D., Hua, S., et al. (2020). The Combination of Orlistat, Lonidamine and 6Diazo-5-Oxo-L-Norleucine Induces a Quiescent Energetic Phenotype and Limits Substrate Flexibility in colon Cancer Cells. Oncol. Lett. 20 (3), 3053-3060. doi:10.3892/ol.2020.11838

Sciacovelli, M., Gaude, E., Hilvo, M., and Frezza, C. (2014). "The Metabolic Alterations of Cancer Cells," in Methods in Enzymology. Editors L. Galluzzi and G. Kroemer (Academic Press), 1-23. doi:10.1016/b978-0-12-4166189.00001-7

Scott, A. J., Song, E. K., Bagby, S., Purkey, A., McCarter, M., Gajdos, C., et al. (2017). Evaluation of the Efficacy of Dasatinib, a Src/Abl Inhibitor, in Colorectal Cancer Cell Lines and Explant Mouse Model. PLoS One 12 (11), e0187173. doi:10.1371/journal.pone.0187173

Senbanjo, L. T., and Chellaiah, M. A. (2017). CD44: A Multifunctional Cell Surface Adhesion Receptor Is a Regulator of Progression and Metastasis of Cancer Cells. Front Cell Dev Biol 5 (18), 18. doi:10.3389/fcell.2017.00018

Shaheen, M., and Broxmeyer, H. E. (2018). "Cytokine/Receptor Families and Signal Transduction," in Cytokine/Receptor Families and Signal TransductionHematology. Editors R. Hoffman, E. J. Benz, L. E. Silberstein, H. E. Heslop, J. I. Weitz, J. Anastasi, et al. (Elsevier), 163-175. doi:10.1016/b9780-323-35762-3.00016-0 
Shiragami, R., Murata, S., Kosugi, C., Tezuka, T., Yamazaki, M., Hirano, A., et al. (2013). Enhanced Antitumor Activity of Cerulenin Combined with Oxaliplatin in Human colon Cancer Cells. Int. J. Oncol. 43 (2), 431-438. doi:10.3892/ ijo.2013.1978

Shiroki, T., Yokoyama, M., Tanuma, N., Maejima, R., Tamai, K., Yamaguchi, K., et al. (2017). Enhanced Expression of the M2 Isoform of Pyruvate Kinase Is Involved in Gastric Cancer Development by Regulating Cancer-specific Metabolism. Cancer Sci. 108 (5), 931-940. doi:10.1111/cas.13211

Si, L., Zheng, L., Xu, L., Yin, L., Han, X., Qi, Y., et al. (2016). Dioscin Suppresses Human Laryngeal Cancer Cells Growth via Induction of Cell-Cycle Arrest and MAPK-Mediated Mitochondrial-Derived Apoptosis and Inhibition of Tumor Invasion. Eur. J. Pharmacol. 774, 105-117. doi:10.1016/j.ejphar.2016.02.009

Smith, B. K., and Steinberg, G. R. (2017). AMP-activated Protein Kinase, Fatty Acid Metabolism, and Insulin Sensitivity. Curr. Opin. Clin. Nutr. Metab. Care 20 (4), 248-253. doi:10.1097/MCO.0000000000000380

Song, M., Bode, A. M., Dong, Z., and Lee, M. H. (2019). AKT as a Therapeutic Target for Cancer. Cancer Res. 79 (6), 1019-1031. doi:10.1158/00085472.CAN-18-2738

Song, Z., Wei, B., Lu, C., Li, P., and Chen, L. (2017). Glutaminase Sustains Cell Survival via the Regulation of Glycolysis and Glutaminolysis in Colorectal Cancer. Oncol. Lett. 14 (3), 3117-3123. doi:10.3892/ol.2017.6538

Spindler, K. L., Sorensen, M. M., Pallisgaard, N., Andersen, R. F., Havelund, B. M., Ploen, J., et al. (2013). Phase II Trial of Temsirolimus Alone and in Combination with Irinotecan for KRAS Mutant Metastatic Colorectal Cancer: Outcome and Results of KRAS Mutational Analysis in Plasma. Acta Oncol. 52 (5), 963-970. doi:10.3109/0284186X.2013.776175

Spriggs, K. A., Cobbold, L. C., Jopling, C. L., Cooper, R. E., Wilson, L. A., Stoneley, M., et al. (2009). Canonical Initiation Factor Requirements of the Myc Family of Internal Ribosome Entry Segments. Mol. Cell Biol 29 (6), 1565-1574. doi:10.1128/MCB.01283-08

Sprowl-Tanio, S., Habowski, A. N., Pate, K. T., McQuade, M. M., Wang, K., Edwards, R. A., et al. (2016). Lactate/pyruvate Transporter MCT-1 Is a Direct Wnt Target that Confers Sensitivity to 3-bromopyruvate in colon Cancer. Cancer Metab. 4, 20. doi:10.1186/s40170-016-0159-3

Steinberg, G. R., and Carling, D. (2019). AMP-activated Protein Kinase: the Current Landscape for Drug Development. Nat. Rev. Drug Discov. 18 (7), 527-551. doi:10.1038/s41573-019-0019-2

Stoneley, M., Subkhankulova, T., Le Quesne, J. P., Coldwell, M. J., Jopling, C. L., Belsham, G. J., et al. (2000). Analysis of the C-Myc IRES; a Potential Role for Cell-type Specific Trans-acting Factors and the Nuclear Compartment. Nucleic Acids Res. 28 (3), 687-694. doi:10.1093/nar/28.3.687

Sung, H., Ferlay, J., Siegel, R. L., Laversanne, M., Soerjomataram, I., Jemal, A., et al. (2021). Global Cancer Statistics 2020: GLOBOCAN Estimates of Incidence and Mortality Worldwide for 36 Cancers in 185 Countries. CA Cancer J. Clin. 71 (3), 209-249. doi:10.3322/caac. 21660

Tabernero, J., Geel, R. V., Guren, T. K., Yaeger, R. D., Spreafico, A., Faris, J. E., et al. (2016). Phase 2 Results: Encorafenib (ENCO) and Cetuximab (CETUX) with or without Alpelisib (ALP) in Patients with Advanced BRAF-Mutant Colorectal Cancer (BRAFm CRC). Jco 34 (15_Suppl. 1), 3544. doi:10.1200/ JCO.2016.34.15_suppl.3544

Tait, S. W., and Green, D. R. (2013). Mitochondrial Regulation of Cell Death. Cold Spring Harb Perspect. Biol. 5 (9), a008706. doi:10.1101/ cshperspect.a008706

Tajirika, T., Tokumaru, Y., Taniguchi, K., Sugito, N., Matsuhashi, N., Futamura, M., et al. (2018). DEAD-box Protein RNA-Helicase DDX6 Regulates the Expression of HER2 and FGFR2 at the Post-Transcriptional Step in Gastric Cancer Cells. Int. J. Mol. Sci. 19 (7), 2005. doi:10.3390/ijms19072005

Tamada, M., Nagano, O., Tateyama, S., Ohmura, M., Yae, T., Ishimoto, T., et al. (2012). Modulation of Glucose Metabolism by CD44 Contributes to Antioxidant Status and Drug Resistance in Cancer Cells. Cancer Res. 72 (6), 1438-1448. doi:10.1158/0008-5472.CAN-11-3024

Tang, J., Yan, T., Bao, Y., Shen, C., Yu, C., Zhu, X., et al. (2019). LncRNA GLCC1 Promotes Colorectal Carcinogenesis and Glucose Metabolism by Stabilizing C-Myc. Nat. Commun. 10 (1), 3499. doi:10.1038/s41467-019-11447-8

Taniguchi, K., Iwatsuki, A., Sugito, N., Shinohara, H., Kuranaga, Y., Oshikawa, Y., et al. (2018). Oncogene RNA Helicase DDX6 Promotes the Process of C-Myc Expression in Gastric Cancer Cells. Mol. Carcinog 57 (5), 579-589. doi:10.1002/ mc. 22781
Taniguchi, K., Sugito, N., Kumazaki, M., Shinohara, H., Yamada, N., Matsuhashi, N., et al. (2015a). Positive Feedback of DDX6/c-Myc/PTB1 Regulated by miR124 Contributes to Maintenance of the Warburg Effect in colon Cancer Cells. Biochim. Biophys. Acta 1852 (9), 1971-1980. doi:10.1016/j.bbadis.2015.06.022

Taniguchi, K., Sugito, N., Kumazaki, M., Shinohara, H., Yamada, N., Nakagawa, Y., et al. (2015b). MicroRNA-124 Inhibits Cancer Cell Growth through PTB1/ PKM1/PKM2 Feedback cascade in Colorectal Cancer. Cancer Lett. 363 (1), 17-27. doi:10.1016/j.canlet.2015.03.026

Templeton, A. J., Diez-Gonzalez, L., Ace, O., Vera-Badillo, F., Seruga, B., Jordán, J., et al. (2014). Prognostic Relevance of Receptor Tyrosine Kinase Expression in Breast Cancer: a Meta-Analysis. Cancer Treat. Rev. 40 (9), 1048-1055. doi:10.1016/j.ctrv.2014.08.003

Thaker, A. I., Rao, M. S., Bishnupuri, K. S., Kerr, T. A., Foster, L., Marinshaw, J. M., et al. (2013). IDO1 Metabolites Activate $\beta$-catenin Signaling to Promote Cancer Cell Proliferation and colon Tumorigenesis in Mice. Gastroenterology 145 (2), 416-4414. doi:10.1053/j.gastro.2013.05.002

Timofeeva, O. A., Tarasova, N. I., Zhang, X., Chasovskikh, S., Cheema, A. K., Wang, H., et al. (2013). STAT3 Suppresses Transcription of Proapoptotic Genes in Cancer Cells with the Involvement of its N-Terminal Domain. Proc. Natl. Acad. Sci. U S A. 110 (4), 1267-1272. doi:10.1073/pnas.1211805110

Tirinato, L., Liberale, C., Di Franco, S., Candeloro, P., Benfante, A., La Rocca, R., et al. (2015). Lipid Droplets: a New Player in Colorectal Cancer Stem Cells Unveiled by Spectroscopic Imaging. Stem Cells 33 (1), 35-44. doi:10.1002/ stem. 1837

To, K. K. W., Wu, M., Tong, C. W. S., and Yan, W. (2020). “Drug Transporters in the Development of Multidrug Resistance in Colorectal Cancer," in Drug Resistance in Colorectal Cancer: Molecular Mechanisms and Therapeutic Strategies. Editors C. H. Cho and T. Hu (Academic Press), 35-55. doi:10.1016/b978-0-12-819937-4.00002-9

Toda, K., Kawada, K., Iwamoto, M., Inamoto, S., Sasazuki, T., Shirasawa, S., et al. (2016). Metabolic Alterations Caused by KRAS Mutations in Colorectal Cancer Contribute to Cell Adaptation to Glutamine Depletion by Upregulation of Asparagine Synthetase. Neoplasia 18 (11), 654-665. doi:10.1016/ j.neo.2016.09.004

Troiani, T., Napolitano, S., Della Corte, C. M., Martini, G., Martinelli, E., Morgillo, F., et al. (2016). Therapeutic Value of EGFR Inhibition in CRC and NSCLC: 15 Years of Clinical Evidence. ESMO Open 1 (5), e000088. doi:10.1136/ esmoopen-2016-000088

Van Cutsem, E., Eng, C., Nowara, E., Swieboda-Sadlej, A., Tebbutt, N. C., Mitchell, E., et al. (2014). Randomized Phase Ib/II Trial of Rilotumumab or Ganitumab with Panitumumab versus Panitumumab Alone in Patients with Wild-type KRAS Metastatic Colorectal Cancer. Clin. Cancer Res. 20 (16), 4240-4250. doi:10.1158/1078-0432.CCR-13-2752

Van der Leek, A. P., Yanishevsky, Y., and Kozyrskyj, A. L. (2017). The Kynurenine Pathway as a Novel Link between Allergy and the Gut Microbiome. Front. Immunol. 8 (1374), 1374. doi:10.3389/fimmu.2017.01374

Vaupel, P., Schmidberger, H., and Mayer, A. (2019). The Warburg Effect: Essential Part of Metabolic Reprogramming and central Contributor to Cancer Progression. Int. J. Radiat. Biol. 95 (7), 912-919. doi:10.1080/ 09553002.2019.1589653

Venkateswaran, N., and Conacci-Sorrell, M. (2020). Kynurenine: an Oncometabolite in colon Cancer. Cell Stress 4 (1), 24-26. doi:10.15698/ cst2020.01.210

Venkateswaran, N., Lafita-Navarro, M. C., Hao, Y. H., Kilgore, J. A., Perez-Castro, L., Braverman, J., et al. (2019). MYC Promotes Tryptophan Uptake and Metabolism by the Kynurenine Pathway in colon Cancer. Genes Dev. 33 (17-18), 1236-1251. doi:10.1101/gad.327056.119

Ventura, R., Mordec, K., Waszczuk, J., Wang, Z., Lai, J., Fridlib, M., et al. (2015). Inhibition of de novo Palmitate Synthesis by Fatty Acid Synthase Induces Apoptosis in Tumor Cells by Remodeling Cell Membranes, Inhibiting Signaling Pathways, and Reprogramming Gene Expression. EBioMedicine 2 (8), 808-824. doi:10.1016/j.ebiom.2015.06.020

Verdaguer, H., Tabernero, J., and Macarulla, T. (2016). Ramucirumab in Metastatic Colorectal Cancer: Evidence to Date and Place in Therapy. Ther. Adv. Med. Oncol. 8 (3), 230-242. doi:10.1177/1758834016635888

Villarino, A. V., Kanno, Y., Ferdinand, J. R., and O'Shea, J. J. (2015). Mechanisms of Jak/STAT Signaling in Immunity and Disease. J. Immunol. 194 (1), 21-27. doi:10.4049/jimmunol.1401867 
Wahlström, T., and Henriksson, M. A. (2015). Impact of MYC in Regulation of Tumor Cell Metabolism. Biochim. Biophys. Acta 1849 (5), 563-569. doi:10.1016/j.bbagrm.2014.07.004

Wainberg, Z. A., Alsina, M., Soares, H. P., Braña, I., Britten, C. D., Del Conte, G., et al. (2017). A Multi-Arm Phase I Study of the PI3K/mTOR Inhibitors PF04691502 and Gedatolisib (PF-05212384) Plus Irinotecan or the MEK Inhibitor PD-0325901 in Advanced Cancer. Target. Oncol. 12 (6), 775-785. doi:10.1007/ s11523-017-0530-5

Walcher, L., Kistenmacher, A. K., Suo, H., Kitte, R., Dluczek, S., Strauss, A., et al. (2020). Cancer Stem Cells-Origins and Biomarkers: Perspectives for Targeted Personalized Therapies. Front. Immunol. 11 (1280), 1280. doi:10.3389/ fimmu.2020.01280

Wang, C., Xie, J., Guo, J., Manning, H. C., Gore, J. C., and Guo, N. (2012). Evaluation of CD44 and CD133 as Cancer Stem Cell Markers for Colorectal Cancer. Oncol. Rep. 28 (4), 1301-1308. doi:10.3892/or.2012.1951

Wang, J., Wang, H., Liu, A., Fang, C., Hao, J., and Wang, Z. (2015). Lactate Dehydrogenase A Negatively Regulated by miRNAs Promotes Aerobic Glycolysis and Is Increased in Colorectal Cancer. Oncotarget 6 (23), 19456-19468. doi:10.18632/oncotarget.3318

Wang, X., Yu, H., Sun, W., Kong, J., Zhang, L., Tang, J., et al. (2018). The Long Non-coding RNA CYTOR Drives Colorectal Cancer Progression by Interacting with NCL and Sam68. Mol. Cancer 17 (1), 110. doi:10.1186/s12943-018-0860-7

Wang, Y., Pan, H., chen, D., Guo, D., and Wang, X. (2021). Targeting at Cancer Energy Metabolism and Lipid Droplet Formation as New Treatment Strategies for Epigallocatechin-3-Gallate (EGCG) in Colorectal Cancer Cells. J. Funct. Foods 83, 104570. doi:10.1016/j.jff.2021.104570

Wang, Z. (2017). "ErbB Receptors and Cancer," in ErbB Receptor Signaling: Methods and Protocols. Editor Z. Wang (New York, NY: Springer New York), 3-35. doi:10.1007/978-1-4939-7219-7_1

Weinberg, F., Hamanaka, R., Wheaton, W. W., Weinberg, S., Joseph, J., Lopez, M., et al. (2010). Mitochondrial Metabolism and ROS Generation Are Essential for Kras-Mediated Tumorigenicity. Proc. Natl. Acad. Sci. U S A. 107 (19), 8788-8793. doi:10.1073/pnas.1003428107

Wen, Z., Zhong, Z., and Darnell, J. E., Jr (1995). Maximal Activation of Transcription by Stat1 and Stat3 Requires Both Tyrosine and Serine Phosphorylation. Cell 82 (2), 241-250. doi:10.1016/0092-8674(95)90311-9

Wilson, J. E. (2003). Isozymes of Mammalian Hexokinase: Structure, Subcellular Localization and Metabolic Function. J. Exp. Biol. 206 (Pt 12), 2049-2057. doi:10.1242/jeb.00241

Wolf, A., Agnihotri, S., Micallef, J., Mukherjee, J., Sabha, N., Cairns, R., et al. (2011). Hexokinase 2 Is a Key Mediator of Aerobic Glycolysis and Promotes Tumor Growth in Human Glioblastoma Multiforme. J. Exp. Med. 208 (2), 313-326. doi:10.1084/jem.20101470

Wolf, E., and Eilers, M. (2020). Targeting MYC Proteins for Tumor Therapy. Annu. Rev. Cancer Biol. 4 (1), 61-75. doi:10.1146/annurev-cancerbio-030518055826

Wolff, R. A., Fuchs, M., Di Bartolomeo, M., Hossain, A. M., Stoffregen, C., Nicol, S., et al. (2012). A Double-Blind, Randomized, Placebo-Controlled, Phase 2 Study of Maintenance Enzastaurin with 5-fluorouracil/leucovorin Plus Bevacizumab after First-Line Therapy for Metastatic Colorectal Cancer. Cancer 118 (17), 4132-4138. doi:10.1002/cncr.26692

Wong, C. C., Qian, Y., Li, X., Xu, J., Kang, W., Tong, J. H., et al. (2016). SLC25A22 Promotes Proliferation and Survival of Colorectal Cancer Cells with KRAS Mutations and Xenograft Tumor Progression in Mice via Intracellular Synthesis of Aspartate. Gastroenterology 151 (5), 945-e6. doi:10.1053/ j.gastro.2016.07.011

Wong, C. C., Xu, J., Bian, X., Wu, J. L., Kang, W., Qian, Y., et al. (2020). In Colorectal Cancer Cells with Mutant KRAS, SLC25A22-Mediated Glutaminolysis Reduces DNA Demethylation to Increase WNT Signaling, Stemness, and Drug Resistance. Gastroenterology 159 (6), 2163-e6. doi:10.1053/j.gastro.2020.08.016

Wu, H., Li, Z., Yang, P., Zhang, L., Fan, Y., and Li, Z. (2014). PKM2 Depletion Induces the Compensation of Glutaminolysis through $\beta$-catenin/c-Myc Pathway in Tumor Cells. Cell Signal 26 (11), 2397-2405. doi:10.1016/ j.cellsig.2014.07.024

Wu, Z., Han, X., Tan, G., Zhu, Q., Chen, H., Xia, Y., et al. (2020). Dioscin Inhibited Glycolysis and Induced Cell Apoptosis in Colorectal Cancer via Promoting
C-Myc Ubiquitination and Subsequent Hexokinase-2 Suppression. Onco Targets Ther. 13, 31-44. doi:10.2147/OTT.S224062

Wu, Z., Wei, D., Gao, W., Xu, Y., Hu, Z., Ma, Z., et al. (2015). TPO-induced Metabolic Reprogramming Drives Liver Metastasis of Colorectal Cancer CD110+ Tumor-Initiating Cells. Cell Stem Cell 17 (1), 47-59. doi:10.1016/ j.stem.2015.05.016

Xiang, L., Mou, J., Shao, B., Wei, Y., Liang, H., Takano, N., et al. (2019). Glutaminase 1 Expression in Colorectal Cancer Cells Is Induced by Hypoxia and Required for Tumor Growth, Invasion, and Metastatic Colonization. Cell Death Dis 10 (2), 40. doi:10.1038/s41419-018-1291-5

Xie, S., Xie, B., Lee, M. Y., and Dai, W. (2005). Regulation of Cell Cycle Checkpoints by polo-like Kinases. Oncogene 24 (2), 277-286. doi:10.1038/sj.onc.1208218

Xu, X., Li, J., Sun, X., Guo, Y., Chu, D., Wei, L., et al. (2015). Tumor Suppressor NDRG2 Inhibits Glycolysis and Glutaminolysis in Colorectal Cancer Cells by Repressing C-Myc Expression. Oncotarget 6 (28), 26161-26176. doi:10.18632/ oncotarget. 4544

Yang, C. L., Zheng, X. L., Ye, K., Ge, H., Sun, Y. N., Lu, Y. F., et al. (2018a). NDRG2 Suppresses Proliferation, Migration, Invasion and Epithelial-Mesenchymal Transition of Esophageal Cancer Cells through Regulating the AKT/XIAP Signaling Pathway. Int. J. Biochem. Cell Biol 99, 43-51. doi:10.1016/ j.biocel.2018.03.003

Yang, P., Li, Z., Fu, R., Wu, H., and Li, Z. (2014a). Pyruvate Kinase M2 Facilitates colon Cancer Cell Migration via the Modulation of STAT3 Signalling. Cell Signal 26 (9), 1853-1862. doi:10.1016/j.cellsig.2014.03.020

Yang, P., Su, C., Luo, X., Zeng, H., Zhao, L., Wei, L., et al. (2018b). Dietary Oleic Acid-Induced CD36 Promotes Cervical Cancer Cell Growth and Metastasis via Up-Regulation Src/ERK Pathway. Cancer Lett. 438, 76-85. doi:10.1016/ j.canlet.2018.09.006

Yang, W., Xia, Y., Ji, H., Zheng, Y., Liang, J., Huang, W., et al. (2011). Nuclear PKM2 Regulates $\beta$-catenin Transactivation upon EGFR Activation. Nature 480 (7375), 118-122. doi:10.1038/nature10598

Yang, W., Zheng, Y., Xia, Y., Ji, H., Chen, X., Guo, F., et al. (2012). ERK1/2dependent Phosphorylation and Nuclear Translocation of PKM2 Promotes the Warburg Effect. Nat. Cell Biol 14 (12), 1295-1304. doi:10.1038/ncb2629

Yang, Y., Su, D., Zhao, L., Zhang, D., Xu, J., Wan, J., et al. (2014b). Different Effects of LDH-A Inhibition by Oxamate in Non-small Cell Lung Cancer Cells. Oncotarget 5 (23), 11886-11896. doi:10.18632/oncotarget.2620

Yao, A., Xiang, Y., Si, Y. R., Fan, L. J., Li, J. P., Li, H., et al. (2019a). PKM2 Promotes Glucose Metabolism through a Let-7a-5p/Stat3/hnRNP-A1 Regulatory Feedback Loop in Breast Cancer Cells. J. Cell Biochem 120 (4), 6542-6554. doi:10.1002/jcb.27947

Yao, Y., Rao, C., Zheng, G., and Wang, S. (2019b). Luteolin Suppresses Colorectal Cancer Cell Metastasis via Regulation of the miR-384/pleiotrophin axis. Oncol. Rep. 42 (1), 131-141. doi:10.3892/or.2019.7136

Yu, H., Pardoll, D., and Jove, R. (2009). STATs in Cancer Inflammation and Immunity: a Leading Role for STAT3. Nat. Rev. Cancer 9 (11), 798-809. doi:10.1038/nrc2734

Yuan, S., Fu, Y., Wang, X., Shi, H., Huang, Y., Song, X., et al. (2008). Voltagedependent Anion Channel 1 Is Involved in Endostatin-Induced Endothelial Cell Apoptosis. FASEB J. 22 (8), 2809-2820. doi:10.1096/fj.08-107417

Yun, J., Rago, C., Cheong, I., Pagliarini, R., Angenendt, P., Rajagopalan, H., et al. (2009). Glucose Deprivation Contributes to the Development of KRAS Pathway Mutations in Tumor Cells. Science 325 (5947), 1555-1559. doi:10.1126/ science. 1174229

Yurgelun, M. B., Kulke, M. H., Fuchs, C. S., Allen, B. A., Uno, H., Hornick, J. L., et al. (2017). Cancer Susceptibility Gene Mutations in Individuals with Colorectal Cancer. J. Clin. Oncol. 35 (10), 1086-1095. doi:10.1200/ JCO.2016.71.0012

Zardavas, D., Phillips, W. A., and Loi, S. (2014). PIK3CA Mutations in Breast Cancer: Reconciling Findings from Preclinical and Clinical Data. Breast Cancer Res. 16 (1), 201. doi:10.1186/bcr3605

Zaytseva, Y. Y., Harris, J. W., Mitov, M. I., Kim, J. T., Butterfield, D. A., Lee, E. Y., et al. (2015). Increased Expression of Fatty Acid Synthase Provides a Survival Advantage to Colorectal Cancer Cells via Upregulation of Cellular Respiration. Oncotarget 6 (22), 18891-18904. doi:10.18632/oncotarget.3783

Zaytseva, Y. Y., Rychahou, P. G., Gulhati, P., Elliott, V. A., Mustain, W. C., O'Connor, K., et al. (2012). Inhibition of Fatty Acid Synthase Attenuates CD44- 
Associated Signaling and Reduces Metastasis in Colorectal Cancer. Cancer Res. 72 (6), 1504-1517. doi:10.1158/0008-5472.CAN-11-4057

Zaytseva, Y. Y., Rychahou, P. G., Le, A. T., Scott, T. L., Flight, R. M., Kim, J. T., et al. (2018). Preclinical Evaluation of Novel Fatty Acid Synthase Inhibitors in Primary Colorectal Cancer Cells and a Patient-Derived Xenograft Model of Colorectal Cancer. Oncotarget 9 (37), 24787-24800. doi:10.18632/ oncotarget.25361

Zhang, M., Ren, B., Li, Z., Niu, W., and Wang, Y. (2017). Expression of N-Myc Downstream-Regulated Gene 2 in Bladder Cancer and its Potential Utility as a Urinary Diagnostic Biomarker. Med. Sci. Monit. 23, 4644-4649. doi:10.12659/ msm.901610

Zhang, X., Blenis, J., Li, H. C., Schindler, C., and Chen-Kiang, S. (1995). Requirement of Serine Phosphorylation for Formation of STAT-Promoter Complexes. Science 267 (5206), 1990-1994. doi:10.1126/science.7701321

Zhang, Z. J., Zheng, Z. J., Kan, H., Song, Y., Cui, W., Zhao, G., et al. (2011). Reduced Risk of Colorectal Cancer with Metformin Therapy in Patients with Type 2 Diabetes: a Meta-Analysis. Diabetes Care 34 (10), 2323-2328. doi:10.2337/ dc11-0512

Zhao, D., Liu, S., Sun, L., Zhao, Z., Liu, S., Kuang, X., et al. (2016). Glypican-4 Gene Polymorphism (Rs1048369) and Susceptibility to Epstein-Barr VirusAssociated and -negative Gastric Carcinoma. Virus. Res. 220, 52-56. doi:10.1016/j.virusres.2016.04.005

Zhao, J., Li, J., Hassan, W., Xu, D., Wang, X., and Huang, Z. (2020a). Sam68 Promotes Aerobic Glycolysis in Colorectal Cancer by Regulating PKM2 Alternative Splicing. Ann. Transl Med. 8 (7), 459. doi:10.21037/ atm.2020.03.108

Zhao, Y., Feng, X., Chen, Y., Selfridge, J. E., Gorityala, S., Du, Z., et al. (2020b). 5Fluorouracil Enhances Antitumor Activity of the Glutaminase Inhibitor CB-
839 against PIK3CA-Mutant Colorectal Cancers. Cancer Res 80 (21), 4815-4827. doi:10.1158/0008-5472.CAN-20-0600

Zhou, Y., Bollu, L. R., Tozzi, F., Ye, X., Bhattacharya, R., Gao, G., et al. (2013). ATP Citrate Lyase Mediates Resistance of Colorectal Cancer Cells to SN38. Mol Cancer Ther 12 (12), 2782-91. doi:10.1158/1535-7163.MCT-13-0098

Zhu, F., Wang, K. B., and Rui, L. (2019). STAT3 Activation and Oncogenesis in Lymphoma. Cancers (Basel) 12 (1), 19. doi:10.3390/cancers12010019

Zou, Y., Du, Y., Cheng, C., Deng, X., Shi, Z., Lu, X., et al. (2021). FAT10 Promotes the Progression of Bladder Cancer by Upregulating HK2 Through the EGFR/ AKT Pathway. Exp Cell Res 398 (1), 112401. doi:10.1016/j.yexcr.2020.112401

Conflict of Interest: The authors declare that the research was conducted in the absence of any commercial or financial relationships that could be construed as a potential conflict of interest.

Publisher's Note: All claims expressed in this article are solely those of the authors and do not necessarily represent those of their affiliated organizations, or those of the publisher, the editors and the reviewers. Any product that may be evaluated in this article, or claim that may be made by its manufacturer, is not guaranteed or endorsed by the publisher.

Copyright $\odot 2021$ Hon, Zainal Abidin, Othman and Naidu. This is an open-access article distributed under the terms of the Creative Commons Attribution License (CC $B Y$ ). The use, distribution or reproduction in other forums is permitted, provided the original author(s) and the copyright owner(s) are credited and that the original publication in this journal is cited, in accordance with accepted academic practice. No use, distribution or reproduction is permitted which does not comply with these terms. 